Portland State University

PDXScholar

4-20-1976

\title{
An examination of the relationship between population density, density related social factors, and physical morbidities
}

Douglas King Huebner

Portland State University

Follow this and additional works at: https://pdxscholar.library.pdx.edu/open_access_etds

Part of the Environmental Public Health Commons, and the Family, Life Course, and Society Commons Let us know how access to this document benefits you.

\section{Recommended Citation}

Huebner, Douglas King, "An examination of the relationship between population density, density related social factors, and physical morbidities" (1976). Dissertations and Theses. Paper 2449.

https://doi.org/10.15760/etd.2446

This Thesis is brought to you for free and open access. It has been accepted for inclusion in Dissertations and Theses by an authorized administrator of PDXScholar. Please contact us if we can make this document more accessible: pdxscholar@pdx.edu. 
AN ABSTRACT OF THE THESIS OF Douglas King Huebner for the Master of Science in Sociology presented April 20, 1976.

Title: An Examination of the Relationship Between Population Density, Density Related Social Factors, and Physical Morbidities:

APPROVED BY MEMBERS OF THE THESIS COMMITTEE:

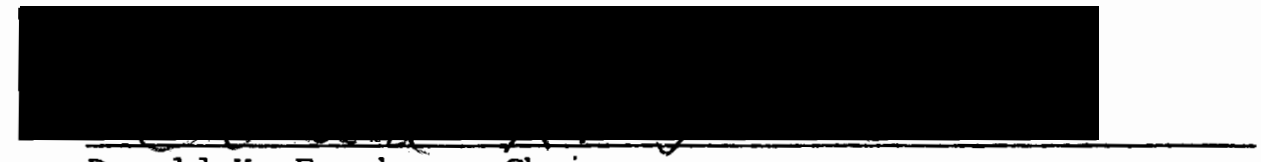

Donald K. Freeborn, Chairman

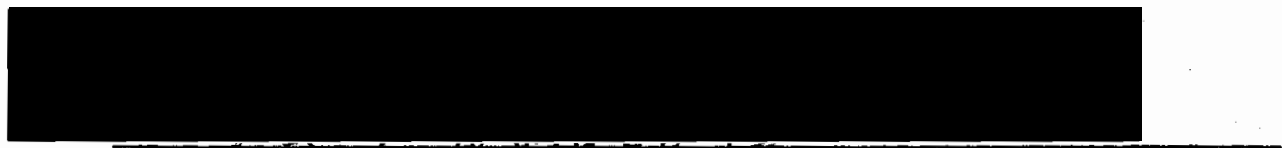

Lee J. Haggefty 77

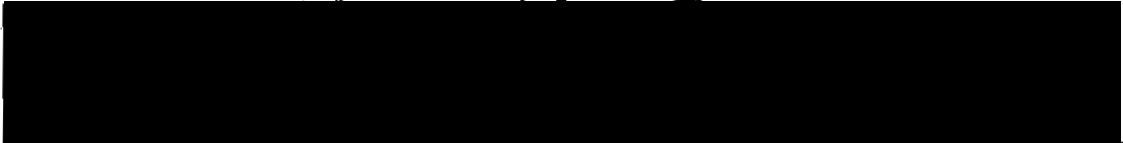

Josfeph F. Jones

The relationship between the number of persons per room in the home and the relative occurrence of stress-related morbidities of hospitalized patients is investigated. The social factors of age, social class, and level of social support also are examined as they relate to both density and morbidity type occurrence. The population under study is composed of all Kaiser-Permanente Medical Care Program members twenty years of age and older, discharged from Bess Kaiser Hospital during 1974, and whose diagnosed morbidity was included in specific morbidity categories. All data were obtained through the facilities of the Health Services Research Center, Kaiser Foundation Hospital, Portland, Oregon. 
The data are largely ordinal in nature, and are presented in the form of contingency tables, utilizing chi square and Tau B as measures of degree of association and strength of relationship. An interval level of measurement is obtained through dichotomization of the variables and the derivation of Pearsonian correlation coefficients, and regression coefficients which are utilized in path analysis.

The findings indicate that higher residential population density is related to disproportionate occurrence of some, but not all, stressrelated morbidities, and that some stress-related morbidities are associated with low population density. However, in comparing stress-related morbidities with non-stress related morbidities, it is found that more stress-related morbidity categories tend to be overrepresented in the higher density regimes than those morbidities categorized as non-stress related. In addition, it is found that those stress-related morbidities that exhibit such a pattern of overrepresentation maintain it, in general, regardless of the controls applied.

Age is found to be negatively related to density and to the occurrence of stress-related morbidities, while being positively related to socioeconomic status. Socioeconomic status is found to be negatively related to both stress-related morbidity occurrence and to density. Social support is positively related to both density and to the occurrence of stress-related morbidities, but appears to have no relationship to either age or class. 
TO THE OFFICE OF GRADUATE STUDIES AND RESEARCH:

The members of the Committee approve the thesis of Douglas King Huebner presented May 21, 1976.

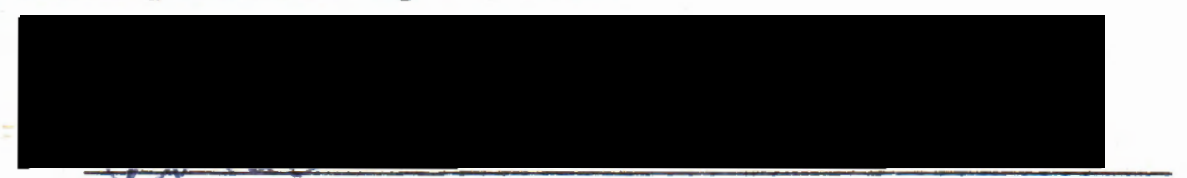

Donald K. Freeborn, Chairman

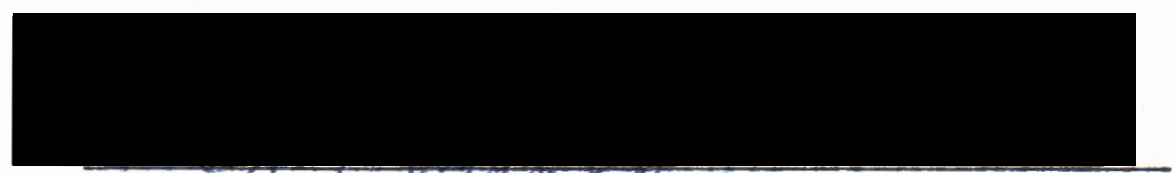

Lee J. Aaggerty

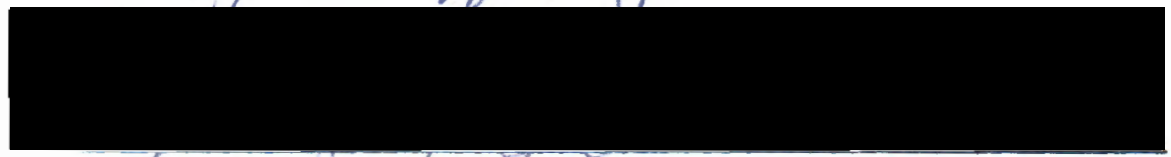

Joseph F. Jones

APPROV

Robert W. Shotola, Head, Department of Sociology

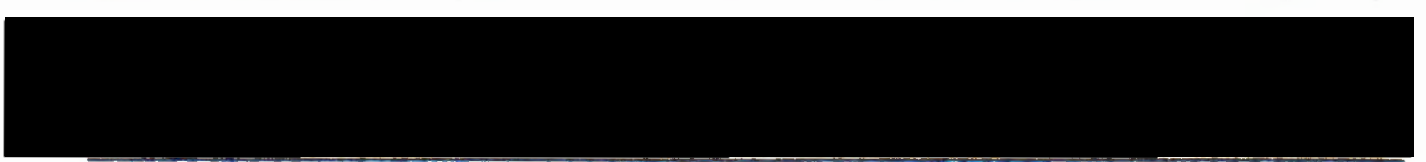

Richard B. Halley, Acting Dean of Graduate Studies and Research 
AN EXAMINATION OF THE RELATIONSHIP BETWEEN POPULATION

DENSITY, DENSITY RELATED SOCIAL FACTORS AND

PHYSICAL MORBIDITIES

by

DOUGLAS KING HUEBNER

A thesis submitted in partial fulfillment of the requirements for the degree of

MASTER OF SCIENCE

in

SOCIOLOGY 


\section{ACKNOWLEDGMENTS}

The writing of a thesis is an undertaking of sufficient complexity and magnitude that the resources of the writer become stretched to their limit, and are at times, exceeded. I wish to express my appreciation to the members of my thesis committee - D.K. Freeborn, L.J. Haggerty, and J.F. Jones - for their constructive criticism of the many drafts of this thesis and for their willingness to share their particular areas of expertise with me. I should also like to thank the Directors of the Health Services Research Center for making their record and computer facilities available to me and to those employees of the Center that spent much time working with me on various data gathering problems. Most of all, I wish to express my thanks and my gratitude to my longsuffering wife, Kittie, who for several months has been a "thesis widow", but without whose emotional support this thesis would not have been written. 
TABLE OF CONTENTS

PAGE

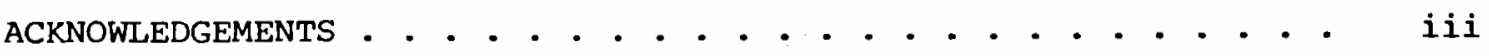

LIST OF TABLES • • • • • • • • • • • • • • • . • • • • • • • • • . v vi

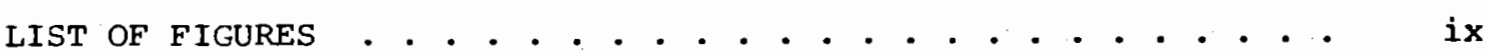

CHAPTER

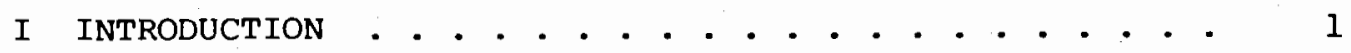

II PHYSIOLOGICAL AND SOCIAL DIMENSIONS OF ENVIRONMENTAL

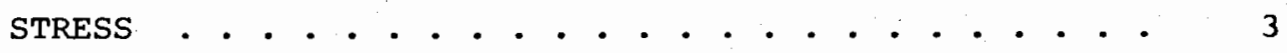

Density, Crowding, and Culture . . . . . . . . 4

Crowding and Social Pathology . . . . . . . . 6

Crowding and stress . . . . . . . . . . . . 7

Territory and Personal Space . . . . . . . . . 9

The Physiology of Stress Response . . . . . . . . 13

Density and stress . . . . . . . . . . . . 18

objectives and Hypotheses . . . . . . . . . . 23

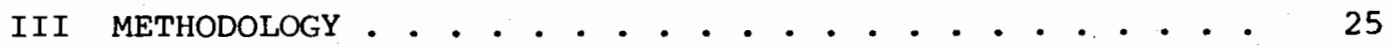

The Research Setting . . . . . . . . . . . . 25

The Health Services Research Center

The Study Population

Data Sources

The Variables . . . . . . . . . . . . . . 28

Stress-Related and Non-Stress Morbidity Types

Age

Social Support 
Population Density

Socioeconomic Status

Operationalization . . . . . . . . . . . . . 32

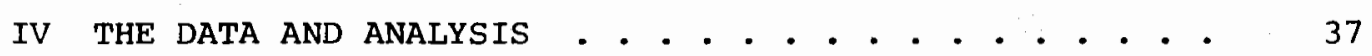

Overview • . . . . . . . . . . . . . . . . 37

Controlled Relationships . . . . . . . . . . 50

Socioeconomic status

Age

Social Support

Analysis of Representative Morbidities

Correlation and Regression Analysis

$\mathrm{V}$ SUMMARY AND CONCLUSIONS ............. 86

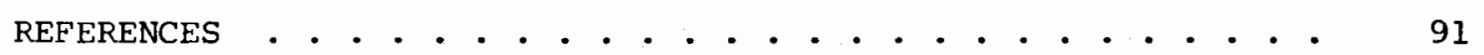

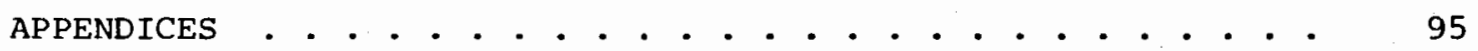




\section{LIST OF TABLES}

TABLE

PAGE

I Operationalization of Variables . . . . . . . . . .

II Stress-Related Morbidity Percentages within Density

Regimes . . . . . . . . . . . . . . . . . . 37

III Deviation Ratios of Stress-Related Morbidities, by

Density Regimes . . . . . . . . . . . . . . . 40

IV Deviation Ratios of Stress-Related Morbidity Categories

Across Density Regimes . . . . . . . . . . . 42

V Deviation Ratios of Non-Stress Related Morbidity

Categories Across Density Regimes . . . . . . . . 45

VI Percentage of Deviation Ratio Patterns Occurring in

Each Morbidity Type . . . . . . . . . . . 46

VII Zero Order Correlations Between Density Regime Midpoints

and the Deviation Ratios of Morbidity Categories .. 48

VIII Comparison of the Number of Morbidity Categories Occur-

ring in Each Group of Correlation Signs by Morbidity

Type, as Listed in Table VII . . . . . . . . . 50

IX Deviation Ratios of stress-Related Morbidities by Density

Regimes and Socioeconomic Status . . . . . . . 51

X Occurrence of Morbidity Types Across Density Regimes by

Levels of Socioeconomic Status . . . . . . . . 52

XI Deviation Ratios of Stress-Related Morbidities Across

Density Regimes, By Age Cohorts . . . . . . . . 54 
XII Weighted Mean Average of the Differences Between Devia-

tion Ratios and Expected Value of 1.000 Across

Density Regimes, By Age Cohort .......... . 56

XIII Occurrence of Morbidity Types Across Density Regimes

By Age Cohort . . . . . . . . . . . 57

XIV Stress-Related Morbidity Occurrence by Density Regime

and Age Cohort............... 58

XV Occurrence of Morbidity Types Across Density Regimes

by Levels of Social Support . . . . . . . . . 59

XVI Deviation Ratios of Stress-Related Morbidities Across

Density Regimes, by Levels of Social Support... . 61

XVII Comparison of Significance Levels of "Ideal Type" Mor-

bidities Across Density Regimes, by Control Variables 64

XVIII Comparison of Percentages of "Ideal Type" Morbidities

Across Density Regimes, by Control Variables . .. 65

XIX Significance Levels for Differences in Percentages of

"Ideal" Morbidity Types Across Density Regimes, by

Control variables ............. 66

XX Deviation Ratios for "Ideal" Morbidity Types Across

Density Regimes, by Control Variables . . . . . 73

XXI Zero Order Correlation Coefficients Between Dichotomized

Variables, as Originally operationalized . . . . 77

XXII Reoperationalization of Dichotomized Variables . . . . 78

XXIII Zero order Correlation Coefficients Between Dichotomized

Variables, as Reoperationalized . . . . . . . 79 
viii

TABLE

PAGE

XXIV Comparison of zero Order Correlation Coefficients and Beta Weights . . . . . . . . . . . . 80

XXV Coefficients of Determination of Independent Variables - 84 


\section{LIST OF FIGURES}

FIGURE

PAGE

1 Theoretical Causal Model of Relationships Between Variables.................. 75

2 Path Diagram for dichotomized variables, as reoperationalized ................. 81 
CHAPTER I

\section{INTRODUCTION}

The primary aim of this thesis is to investigate the relationship between population density in the place of residence and morbidity type occurrence. Because many factors may be involved in disease etfology several characteristics of the respondents which could modify the hypothesized effects of population density are controlled for and taken into account in this analysis. Those characteristics are social class, age, and primary group social support. Population density as a possible etlologlcal factor in disease is of significance for several reasons. The rising population of the world and the increasing trend towards urbanization are placing increasing numbers of people in circumstances of high population density. In the past hundred years, the advances in medical science have eliminated or brought under control many contagious diseases. In the western world, the principal unconquered morbidities are those that involve conditions brought about by causes other than infectious organisms. Some of the more deadly maladies and major health problems, such as heart disease, have been linked to stress development (Aakster, 1974 ; Dodge, 1970; French and Caplan, 1974; Holmes and Rahe, 1967). The identification and specification of environmental conditions that can induce such stress are of vital importance in the epideniology of both stress-related and infectious morbidities. 
Population density is an environmental circumstance that is impinging on the lives of increasing numbers of persons and, barring unforeseen circumstances that drastically reduce world population or current urbanization trends, will continue to be an increasingly present environmental phenomena. Thus the need exists for studies such as this that attempt to isolate the effect of population density on morbidity occurrences. From such investigations can come the knowledge pool upon which both health professionals and public policy makers can draw in the formulation of plans of action aimed at reducing morbidity occurrence and upgrading health standards. In addition, such investigations serve to advance the understanding of sociological phenomena.

In this study, a clear distinction has been made between density and crowding. Density is a measure of the number of persons per unit - mile, acre, block, or room. Crowding, on the other hand, is a human perception of the meaning of any degree of density (Lawrence, 1974). The two terms are not used interchangeably, because each refers to a particular dimension of human experience; density is an objective fact, crowding is a subjective perception. Perceptions can only be inferred, even in the sterile atmosphere of the experimental laboratory, and thus we are reduced to the use of density as a variable by inferring a commonality of perception. That this may not in all cases be warranted is freely admitted, yet the alternative is to hypothesize no commonality of perception; which assertion may be even less defensible. This concept is developed in greater detail in Chapter II. 
CHAPTER II

PHYSIOLOGICAL AND SOCIAL DIMENSIONS

OF ENVIRONMENTAL STRESS

One of the principal problems that arises in attempting to relate an external, environmental condition to a physical, bodily symptom is to provide a linking mechanism by which the objective, external fact becomes transformed into the internal. On the surface of the problem, there seems to be little justification for asserting that sheer population density acts as a noxious environmental stimulus, much less to propose that such an environmental condition could be involved in disease causation. Therefore, a first step in this discussion is to examine the evidence that population density can, under certain conditions, act as an extremely noxious stimulus. Much of the available data links population density with social pathology, and to provide a bridge between a social environment and any physical pathology will require an analysis of the physiological reactions to stressful circumstances in general.

Let us look first at the evidence for density as a cause of social pathology. If the evidence seems to support this relationship, then we are perhaps justified in regarding high population density as a noxious stimulus, or as a stressful environmental element. Since all circumstances of high population density do not result in social pathology, it is evident that some other factor must be differentially 
operative to account for the differences of response to the same levels of density. To arrive at a clearer understanding of the relationship between density and crowding, we must examine this discriminating factor in some detail.

I. DENSITY, CROWDING, AND CULTURE

Cross-cultural studies provide an indication of the nature of the differentiating factor producing different response patterns to the same degree of density. That factor is the cultural definition of the meaning of density. Culture provides the referents necessary for an individual to assign meaning to any level of density. In general, it is culture that determines how the individual will perceive space, that delineates which physical sensors will be used as reliable testimony for such perception, and which provides the symbol sets by which the person relates himself to any space. Thus differential responses to a constant degree of density are found to be a function of how the circumstance is perceived by the organism, and that perception is based on conditioning to culture - specific definitions.

Several studies illustrate the cultural relativity of density interpretation, and the importance of specifying the cultural milieu in which the dense situation occurs. Draper (1973) in his study of the I Kung bushmen found extremely high primary group density with no evidence of either social pathology or biological stress. The average density of occupied dwellings of !Kung camps was 188 square feet per person, compared with 350 square feet per person set as the desirable limit by 
the American Public Health Association. ${ }^{1}$ Although nuclear families dwelt in individual huts, the huts themselves were so close together that items could be passed from one hut to another without a person having to move from a sitting position. The arrangement of huts is such that, for all practical purposes, over thirty people are residing in one large room. Children spend little time in peer group associations, but rather spend most of their time in informal groups which include one or more adults. They all seem to enjoy and to seek closeness and physical overlapping.

Hall (1966) notes that the Dutch and the Germans perceive density by both visual and auditory mechanisms. Hence their buildings are characterized by thick walls to screen noise, and solid doors to match the visual characteristics of the walls. The Japanese, on the other hand, are largely visually oriented. Japanese houses are traditionally composed of moveable inner walls constructed of paper, which provide varied ways to adjust visual spatial arrangernents, yet serve no function in the screening of noise from other areas.

It can be seen from the foregoing, that any attempt to link sheer population density with any human pathological characteristic is pointless without specification of the cultural milieu in which it occurs. Density is important to the individual only if it is perceived as constituting "crowding", or more importantly, "overcrowding".

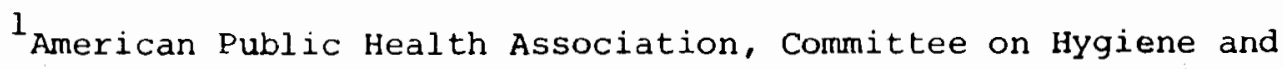
Housing, "Planning the Home for Occupancy", Public Administration Service Pamphlet, Chicago, Ill., 1950. 


\section{CROWDING AND SOCIAL PATHOLOGY}

A number of relationships between crowding and behavioral anomalies have been found in intracultural studies where definitional parameters are assumed to be relatively constant (kdney, 1974; Galle, Gave, and McPherson, 1972). Loo (1972), in relating space to behavioral ac-tivities of children found that males exhibited less aggression under crowded conditions than under less crowded circumstances. Male adaptation in dense circumstances tended to be withdrawal from interaction with others, marked by a decline in group activity and an increase in time spent in solitary play. Surprisingly enough, females showed a significant increase in aggressive behavior in dense circumstances. Another striking result of this study was that females were considerably more consistent in all the other behavioral characteristics measured.

Hutt and Varzec (1966) arrived at some of the same conclusions relative to the relationship of density and differential behavior through an analysis of autistic, brain damaged, and normal children. Their findings indicate that as density increases, there is a significant decrease in aggressive behavior and the number of social contacts among normal children, while brain damaged children exhibited an increase in aggression, and more social contacts in medium sized groups. Autistic children became less socially interactive in large groups, and spent considerably more time at the room boundaries as density increased. In short, physiological characteristics can operate as behavioral determinants in circumstances of certain types of density. 
Thus, the evidence suggests that at some point, physical density becomes perceived by individuals as threatening, evoking behavior patterns designed to adapt the organism through reduction of internal strain, or through modification of the environmental situations into less stressful circumstances. In discussing the difference between population density and the adaptation process brought on by a perception of crowding, Stokols states that:

The experience of crowding, thus, can be characterized as a motivational state directed towards the alleviation of perceived restriction and infringement, through the augmentation of one's supply of space, or the adjustment of social and personal variables so as to minimize the inconveniences imposed by spatial limitations. 1

Hall (1966) lists three options available to an organism in adapting to a stressful circumstance: (1) flight to a less stressful environment, (2) attack, or modification of the environment, or (3) redefinition of the circumstances in such a way that the relationship between the organism and the stressful circumstance is perceived in a less strain-producing manner.

\section{CROWDING AND STRESS}

It would be advisable to consider some reasons as to why crowding should be considered stressful by the organism before embarking on a discussion of the physiological dimensions of stress response. The answers seem to lie on two branches of the same tree; one branch sociocultural and the other biological. The metaphor of the tree and branches

${ }^{1}$ Stokols, D., "On the Distinction Between Density and Crowding: Some Implications for Further Research", Psychological keview, 79, 1972, p. 276. 
is more than "literary license". Rather its aim is to illustrate that although they may be separated in analysis, in the organism they are interdependent and in constant interaction. Even in the process of analysis the distinction is not always clear cut and sharp. We have already examined some of the cultural dimensions of crowding perception. Let us now examine some of the social strains induced by population crowding. Aakster (1974) conceptualizes the human being as an adaptive, telelogically oriented system, with individual, cultural and life-phase related goals. His conception of the well adjusted person involves equilibrium with the environment. External stress is seen as a disequilibrating force. Chief among the stressful social forces are those which lead to conflicting expectations on the parts of group members. A lack of clear cut expectations becomes more intense as the numbers of persons in the group increases. This situation is especially evident in loosely structured groups, where role behavior is generalized rather than specific and where dominance patterns may be shifting and loose. Affective deprivation may occur in circumstances of extreme crowding, as excessive demands are placed on specific individuals, thus inducing in them an "overload" stress, while at the same time rendering them less capable of affective responses towards those persons placing such demands. Lack of clear cut group structure may also lend itself to role conflict. As the number of persons in a group increases, differential requirements are more likely to be imposed on the individual. If social mechanisms are inadequate to handle crowding-induced stress, the indications are that the person has a higher degree of probablilty of developing either 
disease or pathological behavior patterns.

\section{TERRITORY AND PERSONAL SPACE}

Interwoven with the social dimensions of crowding are those dealing with territory and personal space. Let u; first define a territory and then look at some of the evidence as it may apply to man. Lyman (1972), quoting Ardrey (1966) notes that:

"Biology as a whole asks but one question of a territory: is it defensible? Defense defines it. Variability becomes the final description." 1

Sommer (1966) has indicated that territorial behavior in man is limited to those areas which can be controlled by an individual, a family, or other face to face collectivity. Following on this concept of control and defensibility in the human relation to territory, he asserts that extended periods of crowding are necessary before behavioral changes can occur, and that human territoriality as a constant behavioral element becomes evident only under adverse circumstances. Shoemaker (1939) believes that crowding in confinement eradicates territorial boundaries and produces social rank behavior, while Davis (1959) places social rank behavior and territorial behavior on opposite ends of a continuum. closely associated with any territorial behavior found in man is the cultural norm set that predisposes an individual to place emphasis on only some of the environmental characteristics in the

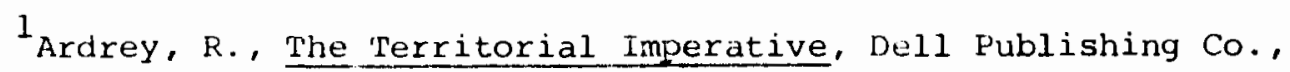
Inc., New York, 1966 quoted in Lyman, Stanford M. and Scott, Marvin B. "Territoriality: A neglected Sociological Dimension", Social Problems, Vol. 15 (12), Fall, 1972 
defining of space in general and territory in particular. Hall (1966) notes that Americans and Europeans are largely "edge oriented" in that they tend to perceive empty space as existing towards the center of a room, with furniture belonging against the walls. Asians, on the other hand, are primarily "center oriented", as they tend to place articles of furniture, cooking devices, etc. towards the center of the room, while the edges are usually bare.

Such spatial perception tendencies are apparently related to the concept of personal space; indeed, personal space has been defined as "portable territory". Envision, if you will, every individual being surrounded by a bubble, and that the space inside this bubble is regarded by the individual as personal property. Intrusion into this personal space creates a stressful circumstance, which prompts an attempt to adapt or re-equilibrate on the part of the individual intruded upon.

Animal studies have indicated that personal space size is speciesspecific, and that some animals can be categorized as touching or nontouching species, with touching species obviously having smaller personal space requirements than non-touching species. A parallel exists in human societies. Hall (1966) notes that western culture is characterized by both non-touching and non-olfactory cultural norms, while the Arab world is largely touching and olfactoraly oriented. Prospective Arab brides have often been rejected because they don't "smell right". To the Arab, specific odors are associated with certain personality characteristics, such as being short-tempered or lazy. 
A further parallel is found in the specific distances involved in the individual definition of personal space. Hall (1966) notes two specific distances related to the personal space of an animal. The first of these, the "flight distance" marks the outer rim of the personal space area. Intrusion of another animal (usually not of the same species) across this invisible line prompts the animal intruded upon to flee. The second of these distances, the "critical or attack distance" marks the closest point that an intruder may venture without being attacked. Citing Heider (1961), Hall notes that these critical distances are so precise that they can be measured in centimeters.

Humans also seem to possess both a flight distance and an attack or critical distance, at least in certain circumstances. Sommer (1966) notes that the flight distance seems to operate in the case of certain types of schizophrenics, who experience something very closely akin to the flight reaction. In describing their feelings when approached too closely by another person, they refer to the event as taking place inside themselves, as if their body extended to the margin of the flight zone. Animals classified as non-contact species consistently maintain physical distance between themselves, such distances being found to be directly related to social structure. Dominant animals possess larger areas of social exclusion than more submissive animals (Calhoun, 1962). Kinzel (1970) noted this same type of personal space requirements in comparing prisoners convicted of violent crimes with those convicted on non-violent crimes. In almost every case, the personal space was significantly larger for violent 
prisoners, with the average personal space area for violent prisoners being 29.3 square feet, while that of non-violent prisoners was only 7.0 square feet. Moreover, the ratio of violent to non-violent areas was 3.8 , based on eight consecutive measurements for each subject (significant at the .05 level). He also found significant differences in the shape of the zones, with those of violent prisoners being larger in the rear than at the front, while those of the non-violent group were larger at the front than at the rear.

Before proceeding to the physiological aspects of denstity or crowding induced stress, a brief summary of the preceeding discussion is in order. First, we have noted that density is only a physical dimension, to be measured in terms of the number of organisms per square unit. Crowding, on the other hand, is a culture-specific perception that assigns an undesirable meaning to density, and that such perception prompts an adaptive response from the individual in an attempt to alleviate the perceived environmental stress. Three functionally adaptive options of response may be available: retreat, attack, or redefinition of the situation. Both personal space and territory are thought to be culturally defined, and are closely related to the perception of crowding. Dominant persons seem to have greater personal space requirements than more submissive individuals. Excessive violations of spatial requirements can create circumstances of such stress content that social pathology emerges either as an adaptation to the stress, or as a result of unsuccessful adaptation. 


\section{THE PHYSIOLOGY OF STRESS RESPONSE}

Having reviewed the evidence indicating that high population density perceived as crowding can constitute a stressful environment element to which the individual attempts to adapt, let us now turn to the physiological aspects of both stress response and the adaptation to such stress. It is in this psycho-physiological response that we will find the link between population density and the development of morbidities.

External stress causes a state of disequilibrium or strain to occur in the individual, which motivates him to attempt to adapt to the stress and reduce or eliminate the strain, thus bringing himself into equilibrium with his environment (Milgram, 1970). The physiological processes which activate automatically once a stressful situation is encountered are reasonably well known from both human and animal studies. (Welch and Klopfer 1961; Welch, 1970; Loo 1974;) 1 . Of key importance to the understanding of stress-induced physiological responses is the fact that such responses are generalized; that is, there is not a specific response to a specific type of stress, and another response to a different kind of stress, but rather the physiological response will be basically the same to a wide variety of stressful circumstances. Animal studies are of great value in this type of study, since their bodies and environments can be manipulated to a relatively limitless degree compared to that which can be accomplished with humans. Because the

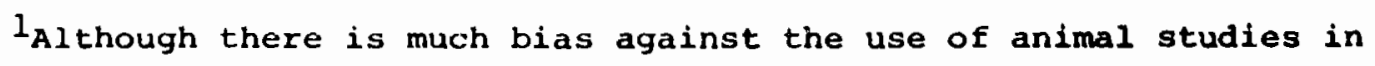
sociological investigations, and in some cases this blas is justified, it seems that such data are clearly relevant to the subject under investigation in this paper, and thus are included. 
physiology of all mammals is fundamentally the same, much can be learned about human physiology through animal studies. This is especially true when examining the physiological reaction to stress. Welch (1964) notes that in every case of stress reaction, a generalized physiological pattern is found in which the parasympathetic and sympathetic subsystems of the autonomic nervous system compete for supremacy. The parasympathetic system initially gains dominance and stimulates the elements of the pituitary-hypothalmus-adrenocortical axis into activity. The hypothalmus secretes a surplus of adrenocorticotropic hormone (АСTH) which stimulates the adrenal cortex to secrete adrenalin into the bloodstream. An excess of adrenalin sets off a chain of other activities throughout the body. The digestive system shuts down, the surface blood vessels constrict, thereby diverting blood to the skeletal muscles, the heart action speeds up, the breathing becomes more rapid, blood pressure increases, stored carbohydrates rush out of the liver and flood the blood with sugar, temperature regulating mechanisms are activated, profuse sweating occurs and the hair stands on end, production of red blood corpuscles is stepped up in both the spleen and red bone marrow, and the time needed for blood coagulation is drastically reduced. All of these responses have survival functions in that they prepare the organism for immediate action. It should also be noted that these responses are not under conscious control, even in a human subject. Once a circumstance has been defined as threatening, the physiological reaction follows automatically.

Evidence for this type of activity abounds in animal research, although evidence with human subjects is less direct. The primary evidence 
of excessive adrenocortical activity in animal studies is found in grossly enlarged adrenal glands, in increased susceptibility to both infectious diseases and neoplasmic morbidities, and in increased death rates. Much of this data has been gained in the laboratory, although there is some evidence from the natural world (christian, 1960). The evidence in regard to human beings stems largely from the use of indicators of adrenocortical activity which do not involve deliberate infection of the subjects. Chief among these indicators are the 17-hydroxycorticosteroids (17-OH-CS) found in both the blood and the urine, and which have shown themselves to be accurate indicators of adrenocortical activity, and hence a measurement of internal strain following upon perceived environmental stress. (Gerard, 1964; Bajuez, 1969). Animal studies (Jensen and Rasmussen, 1970; Taylor and Costanzo 1975) have indicated a parallel secretion of $17-\mathrm{OH}-\mathrm{CS}$ as a response to stress. It may be concluded, in general, that the physiological response to environmental stress is fairly well established in regard to at least some of the bodily systems involved, and that these response patterns cut across species boundaries to establish a basic pattern of physiological similarity in terms both of response and of the pathologies which follow theron.

However, it is a long jump from a mouse to a man, especially in terms of adaptive capacity. The mouse (and all other mammals except man) are prisoners of their genetic makeup, with their najor response patterns set by instinct, with a very limited capacity to learn new responses. Man is usually conceived as lying outside this restriction, being freed from such chains by his ability to define the meaning 
of a situation independent of any genetic programming. The overall response mechanism of a human being is considerably more complex than that of any known animal. The overt response to a given set of circumstances is reasonably predictable with the lower animals. There is a wide scope of evidence to indicate that this is not so with human beings. As previously discussed, the adaptive capacity of man as a species is greatly enhanced by different cultures which provide a variety of response patterns.

Welch (1964), in developing his Mean Level of Environment Stimulation (MLES) concept, found that generalized physiological stress-linked responses varied along a continuum from minimal stimuli situations of sensory deprivation (social isolation) to stimulus overload (overcrowding). Utilizing levels of $17-\mathrm{OH}-\mathrm{CS}$ as the measure of response to stress, he found that such levels changed in a relatively predictable fashion as the environment changed. Such environmental changes included changes in both the social climate and the social structure. Welch found in experiments with mice that the basal level of adrenocortical and adrenalmedullary activity increased across groups, while the endocrine levels of individuals within a group tended to a degree of similarity that reflected the degree of equilibration with the MLES prevailing in the group. Differences within groups tended to vary in a predictable way, depending upon the individual's position in the social hierarchy. Mason (1964) found in working with human subjects, that the 17-OH-CS levels of the members of a B-52 crew on a 22.5 hour flight varied between individuals as a function of the social hierarchy prevailing as a result of rank differences. Using monkeys as subjects, Mason also found that 17-OH-CS 
levels increased as the number of direct or visual only social contacts increased.

In brief, welch's findings indicate that each group tends to establish its own level of endocrine activity as a reaction to its unique MLES. Variation within the group follows a pattern of differences that appears to be a function of hierarchial position. In connection with this, Hill, et. al. (1956) reported a marked uniformity in the cosinophil depression and 17-OH-CS secretion of a winning rowing team working together as a highly organized group in a competitive race. Studies with both mice and men lead to the following propositions:

(1) A group takes on an identity as a distinct entity, which tends to be distinguished physiologically not only from other groups of different size, but also from other groups of the same size.

(2) The MLES is more socially determined in large groups; thus larger groups are more distinctive than small groups.

(3) The prevailing MLES, tension, or social effect is reflected in the physiological behavior of each individual present to a greater or lesser degree.

The primary aim of the foregoing discussion has been to indicate that a large body of scientific data exists that links environmental stress to generalized physiological responses stemming from the action of the autonomic nervous system, and to further indicate that man, as a mammal, is as subject to these responses as is the lowly mouse. It has also served to illustrate some of the social modifiers that operate to intensify or mitigate against strain reactions to environmental stress. Armed with these data, let us now attack the specific 
problem of population density as an important type of environmental stress.

\section{DENSITY AND STRESS}

Animal studies are most indicative of density induced stress, and are perhaps a logical point at which to begin, since culture does not enter into the process to define the meaning of any degree of density, but rather most reactions are built into the animal's instinctual makeup. Christian (1960) examined 244 bodies of sika deer who were the victims of crowded living conditions, and found that enlarged adrenals were present in nearly all of the bodies examined. Of critical importance to the meaning of this study is the fact that these animals died in an environment which could well support their food and water needs. They were, however, situated on an isolated island, rendering the adaptation option of escape impossible. In addition, there were no natural enemies to reduce population. When the population density reached one animal per acre, mortality among the females and the young rose to such levels that the entire herd underwent a population collapse. Every animal examined died from hypoglycemia, a sure indicator of hyperactivity of the adrenocortical system, and a reliable indicator of the presence of environmental stress to which the animal had attempted to adapt. It is interesting to note that the adaptation response was more lethal than the stress which prompted it. It is the contention of this thesis that precisely such a process is at work in human populations, and that the very physiological activities exhibited as a response to overcrowded conditions are in some cases dysfunctional and predispose the human animal to both stress 
diseases and infection related morbidities. Levy and Herzog in their study of the relationship of population density and crowding on health conditions in the Netherlands have asserted that:

". . . there appears to be little doubt that, at least for mammals, high, forcibly maintained densities are quite pathogenic."1

Calhoun (1962) in his famous rat experiment noted both social and physical pathologies resulting from overcrowding, due to the formation of a "behavioral sink" in which the social structures and behavior patterns of rat society were eroded and finally destroyed by excessive population press. Levy and Herzog (1974) note that the development of behavioral sinks among humans may be less obvious due to their higher ability to adapt.

This ability to adapt may, in part, be dependent upon alternatives available. Earlier in this chapter it was mentioned that three options were available to humans in stress adaptation: retreat, attack, or self-environment redefinition. There is some evidence to indicate that high internal density (density in the place of residence) or crowded conditions are tolerable as long as external density is low enough to permit adequate retreat space. Carnahan, et. al. (1974) note that social pathology is lower in rural areas than in urban areas, even though internal density is higher, due partly (they contend) to the existance of very low external density. Draper's study of the !Kung bushmen (1973) illustrates the same point more dramatically. The extremely high internal

$1_{\text {Levy, Leo and Herzog, Allen N., "Effects of Population Density }}$ and Crowding on Health and Social Adaptation in the Netherlands", Journal of Health and Social Behavior, Vol. 15, No. 3, Sept. 1974, p.229 
density previousiy discussed is countered by low external density, each group being separated from the next by a distance of over fifteen miles. Dissatisfied individuals or families move freely between groups. As a result, little stress related morbidity or social pathology is evident. Calhoun's early studies with wild rats (1960) indicate that external density is important in the stabilization of rat social behavior. Wild rats live in colonies of about eleven females and one alpha male. Social behavior in these colonies remains stable as long as external territorial claims can be maintained. In the face of overpopulation conditions, the territories shrink in size, external density increases, and the colonies experience population collapse.

Both territoriality and dominance structures are methods of allocating space. Sommer (1966) has observed that both territoriality and dominance behavior are ways of maintaining a social order, and when one system cannot function, the other takes over. When neither can function, both social chaos and physical morbidities result. Highly dense circumstances may precipitate either social or physical pathologies if the existing instinctive behavior patterns, in the case of animals, or the sociocultural mechanisms, in the case of man, are inadequate to adapt the individual to the situation (Allakian, 1974). Both culture and social factors have been mentioned several times in this chapter as modifiers and interpretational determinants of environmental situations. Let us now examine these factors in more detail, especially as they relate to stress development. In examining some of the sociocultural factors related to hypertension among urban and rural 
Zulus, Scotch (1963) found that the development of hypertension among urban Zulus was largely a result of an inability to adapt to the urban environment. Interestingly enough, neither education, urban-rural preference, nor socioeconomic status were related to hypertension in either rural or urban dwellers. Among urban zulus, the greatest contributors to hypertension were increased age, marital status (females only), large numbers of children (females only), income of the male (affected wives only), family type (extended family having higher rates than a nuclear family) and length of urban residence (males only). Among rural dwellers, the most outstanding difference was found in widowed and separated females. In each locality, church attendance was negatively correlated with hypertension for females, and positively correlated for males. Aakster (1974) related several specific health disturbances to various social factors. One of the social factors which correlated most highly was that of poor parental family integration, or poor relationships with the parents at the time of the study. Of almost equal frequency was status dissatisfaction, usually coupled with low status mobility. Dodge (1970) has linked status and role conflict to the development of several stress related morbidities: arterio-heart disease, malignant neoplasms, cirrhosis of the liver, diabetes melletus, leukemia, and aleukemia. Jensen and Rasmussen (1970) found that susceptibility to viral infections in mice was increased when subjects were exposed to long periods of sound stress. It was also found that intermittent stressing was more effective in increasing susceptibility than continuous stressing. The indication is that continuous stress is more easily adapted to than intermittent stress, and that the anticipation of stress 
may be as important as the occurrence of the event itself.

Welch (1964) found that the dying time of mice injected with d-amphetamine was considerably greater if they had lived in groups of five for five weeks prior to the injection, than if they had lived in isolation for the same period of time. Taylor and Costanzo (1975) compared stable dominant-subordinate pairs of rats and found the greatest physiological response to stress among the dominant subjects, while the least amount of stress was found among isolate reared subjects. This study, when compared with that of Welch discussed above, seems to indicate that the existence of population induced stress and the physiological response thereto may have some survival value in that it preconditions the organism to greater degrees of resistance. Welch proposes that the optimum level of stress is found in a median range; that population extremes are most associated with morbidity.

The presence of meaningful social support is related to this median range of population density. Inadequate social interaction seems to predispose an individual to morbidities with a high psychological content (Gillis, 1974; Kaplan, 1963) while excessive population density is associated with a variety of morbidities, both stress-related and infectious in nature (Levy and Herzog, 1974). Cassel (1964) has gone a step further in asserting that density per se is simply an environmental characteristic associated with certain types of social interactive patterns, and that it is these patterns that create or alleviate stress. He mentions the degree of social support as one of these interactive patterns that may be closely associated with stress alleviation, and that to analyze population density and stress development without 
reference to such interactive factors is to possibly bypass the primary causative agent. Stokols (1972) supports this view when he notes that the response to dense circunstances is a function of the relative intensity of spatial, social, and personal factors, and the degree to which they can be modified. He goes on to point out that circumstances that may seem stressful to an outside observer may not be so to the participant if the relationships with others are friendly and cooperative.

Strong social support is regarded in this thesis as a beneficial factor, mitigating against the development of morbidities at all levels of density. The details of the factor, as well as the contents of the other social variables deemed important as modifiers are delineated in the following chapter.

\section{OBJECTIVES AND HYPOTHESES}

The objectives of this study are two-fold. The primary thrust of the investigation is to relate population density and morbidity type occurrence. This first analysis asks the question "What is the relationship between population density in the home and the relative occurrence of stress-related and non-stress related morbidities?". The second purpose of this investigation is to analyze some of the correlates of various population densities, and at the same time to investigate how other social variables interact with both population density and morbidity, as well as with each other.

Although the methodological approach in this paper is not based on deductive reasoning, and thus does not involve hypothesis testing 
in a formal sense, it is sometimes useful to state objectives in the form of hypotheses for purposes of clarity of intent and to point up conceptual relationships that have determined the variables chosen for study. The hypotheses are as follows:

(1) Other variables being equal, higher levels of density will be associated with disproportionately large numbers of stress-related morbidities.

(2) Since definitions of the environment are culture-specific (Hall, 1966), the possibility of differential definition by social class (sub-culture) gives rise to:

a. Other variables being equal, higher levels of socio-economic status are associated with disproportionately greater numbers of stress-related morbidities.

b. High degrees of density should be interpreted by upper class groups as being more stressful than the same degree of density for lower class groups. This may be associated with a variety of status inconsistency (Levy and Herzog, 1974).

(3) Age is inversely related to social support at either extremes (young adult and elderly adult categories).

(4) Other variables being equal, higher levels of social support will be associated with disproportionate numbers of stress-related morbidities.

The foregoing hypotheses have structured the methodology outlines in the following chapter. Although the variables are largely stated in qualitative terms, they may nevertheless serve a purpose in directing attention to general trends and overall relationships. 
CHAPTER III

METHODOLOGY

I. THE FESEARCH SETTING

The Health Services Research Center

All data utilized in this thesis were obtained through the facilities of the Health Services Research Center, Kaiser Foundations Hospitals, Portland, Oregon. The Health Services Research Center is an integrated research facility that has as its research setting an organized medical care system that provides comprehensive medical services to a known population. The Center has conducted medical care research within the Kaiser-Permanente Medical Care System for more than a decade. A unique resource of the Center is the objective, extensive, and reliable source of base-line population and medical care data. An inpatient research information system has been operational for ten years. Using an available computer system, social, economic, situational and medical care data for each of the last 150,000 consecutive hospital discharges from the Bess Kaiser Hospital have been recorded.

The Kaiser-Permanente Medical Care Program

The Kaiser-Permanente Medical Care Program is a prepaid group practice and is considered to be a prototype health maintenance organization. It is characterized by five basic principles that have shaped the organization of this system: voluntary enrollment, prepayment for 
comprehensive benefits on a service basis, preventative medical care, integrated, hospital-based health care facilites, and provision of physician services through group medical practice. ${ }^{1}$

The demographic and socioeconomic characteristics of the Health Plan membership very closely correspond to the metropolitan population as a whole. Thus, the Health Plan membership provides a well defined population base with known dynamic properties.

\section{The Study Population}

The population under examination in this thesis consists of all health plan members discharged from Bess Kaiser Hospital, Portland, Oregon, during the entire year 1974. From this basic population several exclusions have been made. The study population does not include patients under twenty years of age, those whose discharge diagnosis was related to pregnancy, and those discharges of extended care patients.

\section{Data Sources}

Each inpatient record consists of information derived from two separate data forms; The Patient Personal History Questionnaire and the Discharge Summary. The source of all social data is the Patient Personal History Questionnaire, which was filled out on all inpatients in the study population by the patient or his family sometime during the hospital stay (see Appendix A). Patients are not asked to complete another questionnaire if they have completed one during a hospital admission within the past six months. A response rate of

1 sommers, Anne R., (editor) The Kaiser-Permanente Medical Care Program, The Commonwealth Fund, New York, N.Y., 1971 
greater than 90 per-cent is experienced on these questionnaires.

The source of the morbidity information is the Discharge Summary section of the Patient Personal History Questionnaire which lists both the diagnosis and the medical action taken. (See Appendix B). The Discharge Summary is completed by a research medical record technician. Medical information is transferred from the patient's official hospital record to this research form. Included are, among other things, admission and discharge dates, admitting and discharge diagnoses, physician number and service, consultations and surgical and laboratory procedures. The International Classification of Diseases, Adapted, (ICDA), 3th edition codes are used to code diseases and surgical procedures. Several items of information have been selected from the Patient Fersonal History Questionnaire to operationalize the concepts investigated in this study. The specific items and the method of operationalization are discussed in detail later in this chapter. These data are presented in three parts. The first part presents ordinal data in expanded form, relating twenty-four disease catagories to various levels of density. Both chi square and Tau B are utilized as measures of relationship. Part two of the analysis collapses the data into dichotomies. Chi square is used throughout this second section, and from this measure phi square, phi, and Pearsonian correlation coefficients are derived. The availability of such correlation coefficients enables the calculation of Beta weights for use in path analysis techniques which place the relationships in a quantitative perspective not possible in either part one or part two. 


\section{THE VARIABLES}

\section{Stress-Related and Non-Stress Morbidity Types}

Although both types of disease may be related in some degree to environmental stress, some diseases are probably more closely related to stress than are others (Aakster, 1974; Dodge, unpublished article). Various conditions of the body, such as heart disease or some organ or system malfunctions that are not contagious may be more closely related to stress than are those which involve some type of disease transmission, or which involve trauma (Scotch, 1963; Theorell and Rake, 1971).

There is some evidence to indicate that stress reduces resistance to contagion (Jensen and Rasmussen, 1970; Friedman and Glasgow 1966; Solomon and Amkraut, 1974), but the relationship seems to be less direct than that of stress related morbidities. The division of disease types is not completely clear, but with some notable exceptions such as tuberculosis, there is little consensus within the medical profession as to the placement of morbidity types on any stress continuum. The dichotomization of morbidities in this study has been made on the basis of the research results that are available on the subject (Dodge, unpublished manuscript; Levy and Herzog, 1974; Scotch, 1963; Tinbergen, 1974; Theorell, 1971).

Age

Increased age can be regarded as being related to many types of morbidities. Diseases of a degenerative nature are more frequent in the elderly than the young. It is hypothesized that older persons are 
less capable of eliciting equilibrating adaptive responses than are younger persons. Age may also be regarded as a determinant of some of the components of socioeconomic status. In addition, age may affect the amount of social support available to the patient. The elderly adult may encounter less social support than a younger adult in view of the frequent practice of non-home care for the elderly. Also, the elderly are more likely to be widowed, thus eroding a primary source of social support - that of the spouse - while the younger adults are less likely to have been married.

\section{Social support.}

The term social support is used to indicate the degree to which the patient has been surrounded by significant others with whom strong affective ties may be presumed to exist. It is hypothesized that the presence of such persons in the patient's daily life serve as a modifier of density induced stress in a number of ways. First, if these persons live in the same house as the patient, their presence would be less stressful than if the patient were housed with strangers, or those with whom only secondary relationships existed. Thus the presence in the home of spouse and children would obviously increase density, but could at the same time create circumstances of emotional security that aid in the patient's functional adaptive response to such density. In addition, the less formal role requirements placed on members of primary groups could give to the patient a wider range of possible adaptive responses to density-induced stress, thus reducing the possibility of stress buildup and subsequent morbidity occurrence. Because the data do not indicate the state of such support prior to 
the patient's admittance to the hospital, the existence of such support can only be inferred by examining the social support available after discharge. There are some serious limitations to this approach. In some cases, it may well be that the social support available after discharge was motivated by the supporter's response to the hospitalization of the patient, and thus does not reflect the prehospitalization conditions.

A second objection deals with the condition of pre-admittance population density and the amount of help available after discharge. A reasonable case could be made that both variables are varieties of the same phenomena. If a great deal of help is available after the patient's discharge, it may be due to the fact that such helpers are members of the patient's primary group, opening up the possibility that such persons contributed to the home density that is hypothesized to be related to the occurrence of the morbidity. However, the hypothesized relationship between density and social support is that a high degree of social support dilutes the stressful effect of density. Although the data source does not allow a more accurate determination of the pre-admission circumstances, these alternative explanations should be borne in mind in the interpretation of any results.

Social support is conceptualized in this study as an intervening variable, the qualities of which are independent of density, with definitional characteristics that are only marginally related to home density.

\section{Population Density.}

As was discussed in Chapter II, density is a necessary but not sufficient requisite for the development of crowding stress. Density 
becomes stressful only when persons involved define such density as crowded and undesirable, and when no functionally adaptive options are available. It is not possible from the data at hand to determine the existence of other options. It must therefore be presumed that these options are so distributed as to not affect the development of density related stress.

The particular mechanism of measurement employed, that is, persons per room, leaves many dimensions of spatial perception untouched. Both the size and arrangement of rooms, as well as the way in which they are furnished, the color of the walls, and the level of noise could all contribute to the outcome of the definitional process. However, these data are not available. Thus we are reduced to using what is admittedly a less desirable yardstick than might otherwise be utilized. Any conclusions reached as a result of this study must therefore be modified accordingly.

\section{Socio-Economic Status}

There is some evidence to suggest that the meaning of any degree of density is subject to culture-specific definitional processes (Hall, 1966; Sommer, 1966; Altman, 1975). The broad definitional processes are presumed to be a regional constant in this thesis. However, different value sets within social classes may act to produce class-specific interpretational schemes. Because density is only a physical, structural factor, it is necessary to infer the interpretational process that defines density as crowded (and thus stressful). Social class differences may offer a mechanism to aid in this inferential process.

Social class may be inversely related to density in that larger, 
more spacious houses usually cost more and thus may be out of reach of those with lower incomes. In addition, lower class families usually have more children than upper classes, thereby compounding the density created by houses with fewer rooms.

Socio-economic status, or social class, then may serve to highlight intragroup density-morbidity relationships, as well as serving as a vehicle for pointing up interclass differences which may give some clue to any class-specific interpretational processes. This latter point indicates that there may also be class-specific differences in social support, given any degree of density.

\section{OPERATIONALIZATION}

The variables have been operationalized according to the rationale presented in Part 1 of this chapter. Although the original data source was the Patient's Personal History Questionnaire, the encoding process that transferred the data to computer tapes utilized the SPSS system, in which base data were manipulated to provide additional data not shown on the original document. For example, the Patient's Personal History Questionnaire indicates the number of rooms in the dwelling and the number of people that reside therein, but it does not indicate the number of people per room. That specific bit of data is computed as a new item of information before being put on the computer tape. Therefore reference to the sample of Patient's Personal History Questionnaire (Appendix A) will not provide this particular item of information. Other factors, such as occupation and education, are also manipulated and categorized into specific classes before being entered into the computer records from which all data are drawn. 
Two of the variables - social support and socioeconomic status involve scales. These scales are composed of a number of items to which various weights have been assigned. Categorization into the various ordinal levels of each of these variables is determined by totaling the weights of the variable elements.

It should also be noted that two separate operationalizations of density appear. Density la utilizes the full range of density categories available from the data source. Density $1 \mathrm{~b}$ dichotomizes the variable at .51 persons or more per room. In the tables presented in Chapter IV, which operationalization of density is being analyzed will be clearly stated to avoid any possible confusion. The dichotomization at 0.51 persons per room is approximately at the median of the density regime distribution. The full range of density is utilized to provide the maximum amount of information in the development of patterns of morbidity distribution. The dichotomy is utilized in two by two tables to obtain correlation coefficients and regression coefficients for use in path analysis.

TABLE I

OPERATIONALIZATION OF VARIABLES

\begin{tabular}{|c|c|c|c|}
\hline $\begin{array}{l}\text { Var. } \\
\text { No. }\end{array}$ & $\begin{array}{l}\text { Var. } \\
\text { Title }\end{array}$ & $\begin{array}{l}\text { Var. } \\
\text { Unit }\end{array}$ & operationalization \\
\hline $1 a$ & Density & $\begin{array}{l}\text { Persons } \\
\text { per room }\end{array}$ & $\begin{array}{l}0.00 \text { to } 0.25 \text { - Very Low } \\
0.26 \text { to } 0.50 \text { - Low } \\
0.51 \text { to } 0.75 \text { - Moderately Low } \\
0.76 \text { to } 1.00 \text { - Medium } \\
1.01 \text { to } 1.50 \text { - Moderately High } \\
1.51 \text { to } 2.00 \text { - High } \\
2.01 \text { or more - Very High }\end{array}$ \\
\hline $1 \mathrm{~b}$ & $\begin{array}{l}\text { Density } \\
\text { Dichotomy }\end{array}$ & $\begin{array}{l}\text { Persons } \\
\text { per room }\end{array}$ & $\begin{array}{l}0.00 \text { to } 0.50 \text { - Lower } \\
0.51 \text { or more - Higher }\end{array}$ \\
\hline
\end{tabular}


TABLE 1 (CONT'D)

OPERATIONALIZATION OF VARIABLES

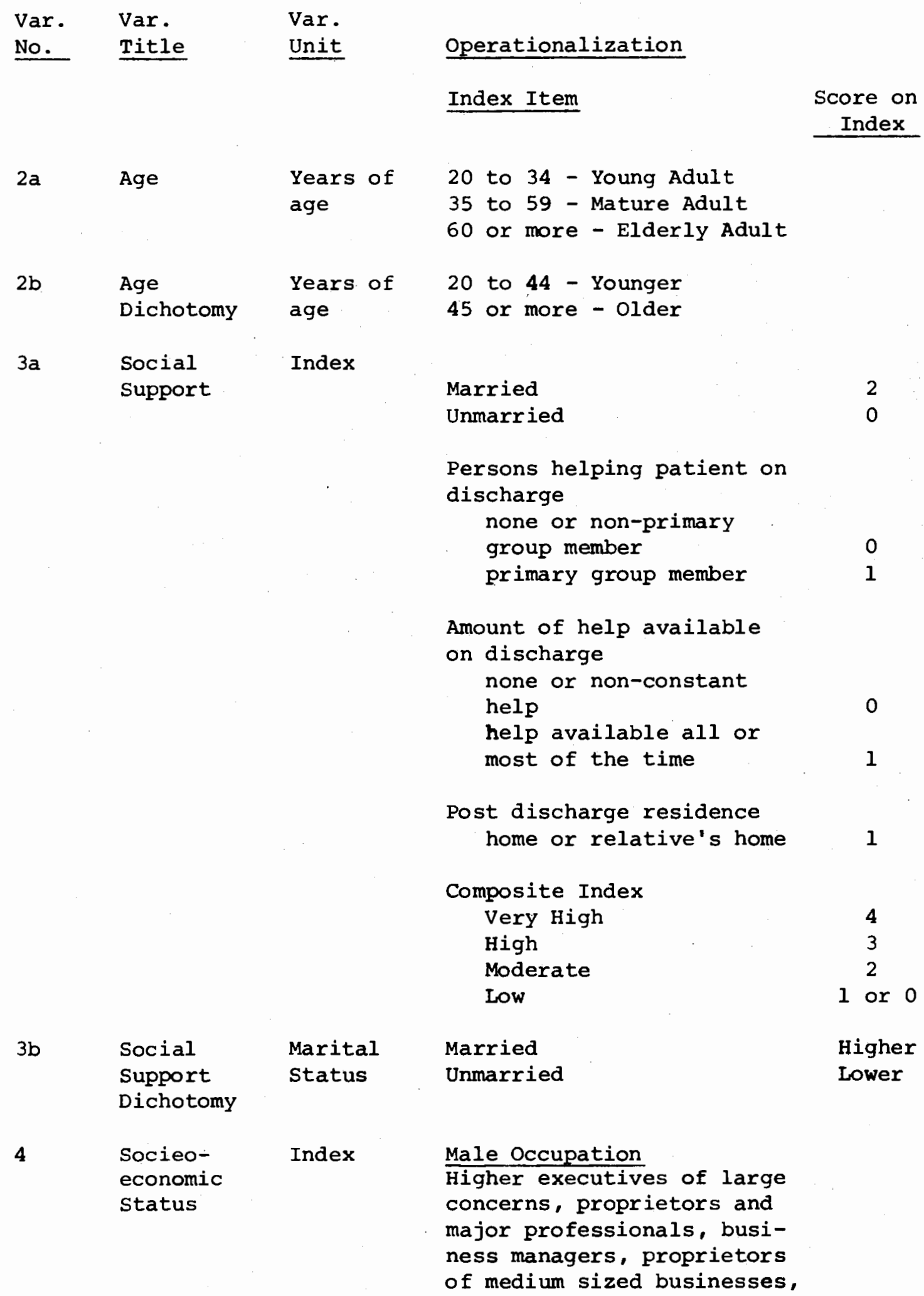


TABLE 1 (CONT'D)

\section{OPERATIONALIZATION OF VARIABLES}

Var. Var.

Var.

No. Title

Unit

Operationalization

Index Item

Score on

Male Occupation

Socieo- Index

Economic

lesser professionals

Administrative personnel, owners of small businesses, minor professionals, clerical and sales workers, technicians, owners of little businesses, skilled manual employees

Machine Operators, semiskilled and unskilled, not employed with no previous employment

Female Occupation

Same as male occupational categories. Used only if female patient is unmarried. For married female patients, occupation of husband used on index.

Male Education

College graduate

Some college or post high school training

High school graduate

Non-high school graduate

Female Education

Same as male education categories. Used only if female is unmarried. For married female patients, education of husband used on index.

Total Annual Family Income Greater than $\$ 15,000$ $\$ 7500$ to $\$ 15,000$

Less than $\$ 7500$ 
TABLE 1 (CONT'D)

OPERATIONALIZATION OF VARIABLES

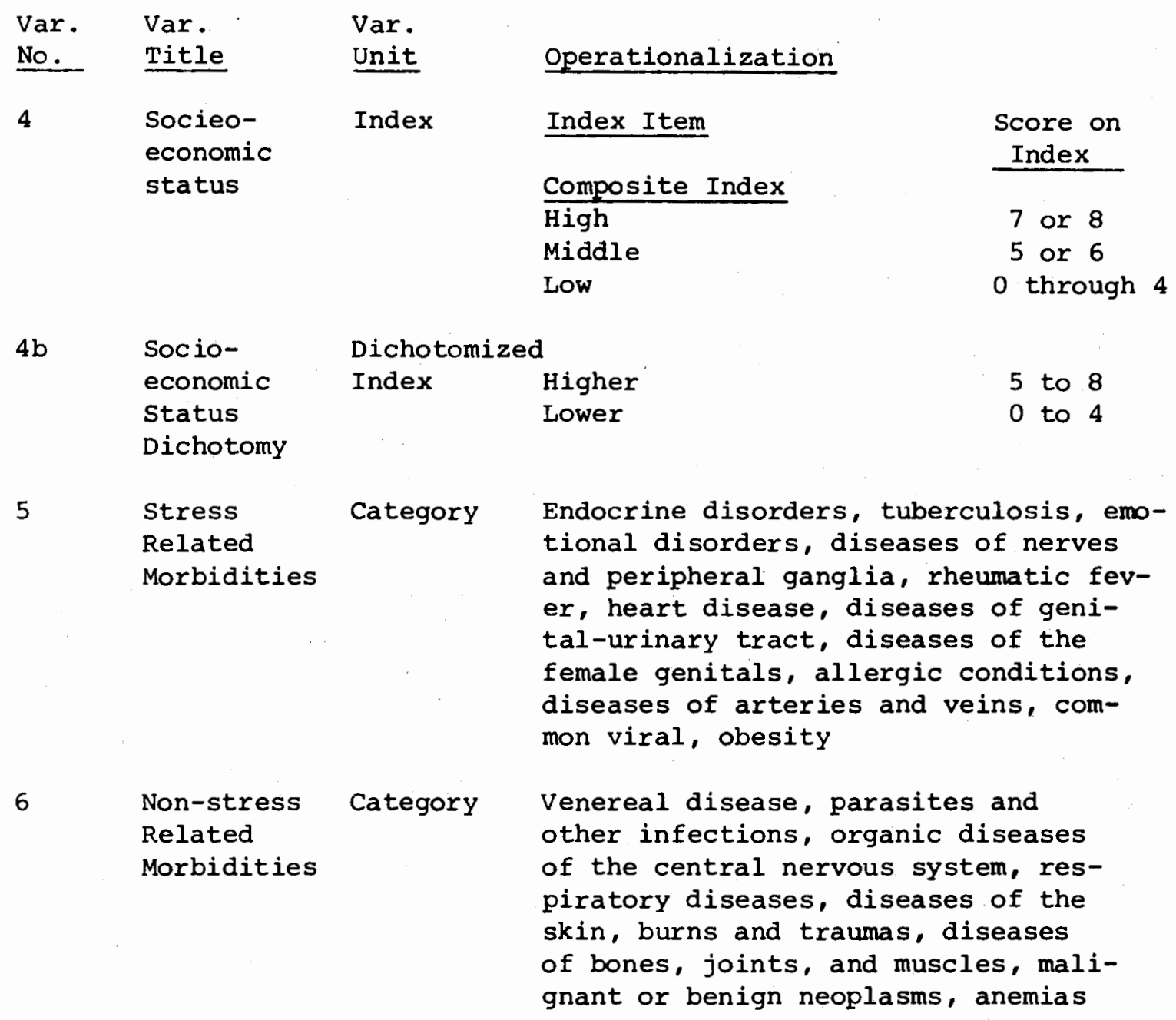


CHAPTER IV

THE DATA AND ANALYSIS

I. OVERVIEW

Let us begin the data presentation with an overview of the basic hypothesis underlying this thesis - that high population density in the home is related to a disproportionate occurrence of stress-related morbidities. Table II indicates the percentages of stress related morbidities occurring in each density regime. The percentages do not indicate the distribution of stress-related morbidities across density regimes, but rather the occurrence of each morbidities within each density regime. For example, in the "0.26 to 0.50 " density regime, 51 percent of the patients living in that density regime were hospitalized for stress-related morbidities. This would indicate that 49 percent of the patients living in that density regime were hospitalized for non-stress related morbidities.

TABLE II

STRESS-RELATED MORBIDITY PERCENTAGES WITHIN DENSITY REGIMES

\begin{tabular}{|c|c|c|c|c|c|c|c|}
\hline \multicolumn{8}{|c|}{ Density Regime } \\
\hline $\begin{array}{l}\text { Morbidity } \\
\text { Type }\end{array}$ & $\begin{array}{c}\text { Less Than } \\
0.26\end{array}$ & $\begin{array}{l}0.26 \text { to } \\
0.50\end{array}$ & $\begin{array}{l}0.51 \text { to } \\
0.75\end{array}$ & $\begin{array}{l}0.76 \text { to } \\
1.00\end{array}$ & $\begin{array}{l}1.01 \text { to } \\
1.50\end{array}$ & $\begin{array}{l}1.51 \text { to } \\
2.00\end{array}$ & $\begin{array}{l}\text { More } \\
\text { Than } \\
2.00\end{array}$ \\
\hline $\begin{array}{l}\text { Stress- } \\
\text { Related }\end{array}$ & $\begin{array}{r}48.88 \\
(385) \\
\end{array}$ & $\begin{array}{l}51.0 \\
(1753) \\
\end{array}$ & $\begin{array}{l}511 \\
(660) \\
\end{array}$ & $\begin{array}{l}41.2 \\
(278) \\
\end{array}$ & $\begin{array}{r}51.2 \\
\quad(62) \\
\end{array}$ & $\begin{array}{r}36.4 \\
(4) \\
\end{array}$ & $\begin{array}{r}100.0 \\
(31) \\
\end{array}$ \\
\hline $\begin{array}{l}\operatorname{ase} \mathrm{N} \\
\operatorname{ptal} \mathrm{N}\end{array}$ & $\begin{array}{l}789 \\
27\end{array}$ & 3483 & 1291 & 674 & 121 & 11 & 3 \\
\hline
\end{tabular}


Several items of information can be noted from Table II. First, there appears to be little pattern in the percentages across the various density regimes. Only two density regimes have substantial differences: "0.76 to $1.00 "$ and "1.51 to 2.00". Although the "more than $2.00 "$ regime has 100 percent of the cases in that density regime, it should be noted that such a percentage is based on only three cases. It would be expected, on the basis of the hypothesis, that the percentage of all morbidities which are stress-related would increase as density increases. This is clearly not the case.

Note that in Table II, the percentages of all reported diseases which are stress related is a function of the numbers of non-stress related morbidities as well as density. To remove the possible confounding effects of the differential occurrence of non-stress related disease on the percentages indicating stress-related occurrence, the distribution of stress-related diseases only across different levels of household density will be examined. However, since it would be expected that a greater number of morbidities of any type (stress or non-stress) would occur in density regimes having a greater number of people, we must take this fact into account. Since the respondents being analyzed here are distributed according to household density generally in the same relative proportions as the population of Portland, Oregon, we have computed ratios indicating the extent to which a particular density regime shows an over or under representation of stress-related disease from what we would expect from the number of people exposed to that regime.

1. SMSA Census Report, 1970, Oregon. See Appendix C 
This ratio represents the percentage of stress related cases within each stress-related density regime cell to the total percentage of all morbidities in the entire density regime, on the theory that if there existed no relationship between the degree of density and morbidity type occurrence an equal percentage of the morbidity marginals would occur as a function of the density percentage. For example, we find from Table II that 385 patients living in the "less than 0.26 " regime had stress related diseases, while 789 patients lived in that regime, regardless of the type of morbidity exhibited. In percentage terms, 12.5 percent of the total patients lived in homes with less than 0.26 persons per room. Examining the occurrence of stress related morbidities in terms of percentages, we find that 385 persons, or 12.2 percent of those with stress-related morbidi: ties lived in that density regime. The ratio of 12.2 percent to 12.5 percent is termed the "deviation ratio" and is in effect a measure of underloading or overloading of stress-related morbidities, based on the percentage expected if morbidities were distributed on the basis of the density percentages only. Returning to the example of density regime "Less than 0.26 " we find the ratio of 0.982 , indicating a slight underrepresentation. If there were perfect correspondence, the ratio would obviously be 1.000. Therefore ratios less than 1.000 are underloaded, those greater than 1.000 are overloaded. Table III presents these ratios for density regimes and stress-related morbidities. 
TABLE III

DEVIATION RATIOS OF STRESS-RELATED MORBIDITIES, BY DENSITY REGIMES

Density Regime Deviation Ratio

Less than $0.26 \quad 0.976$

0.26 to $0.50 \quad 1.028$

0.51 to 0.75

0.76 to $1.00 \quad 0.812$

1.01 to $1.50 \quad 1.003$

1.51 to $2.00 \quad 0.500$

More than $2.00 \quad 2.021$

From Table III it can be seen that the deviations from the expected value of 1.000 are quite small in most cases. This is most noticeable in regimes less than 0.76 . The regime of "0.76 to $1.00 "$ is worthy of note, as it deviates from the expected value by -0.188 . Also note that although the intervening range of " 1.01 to $1.50 "$ is almost exactly the expected value, higher ranges deviate much more widely, but in differing directions. The " 1.51 to $2.00 "$ regime is much less than expected, while the "Greater than 2.00 " regime is more than twice the expected value. In view of these data, a tentative alternative hypothesis can be formulated to the effect that wide deviations from the expected value tend to be found in the upper regions of density, although at this point, no explanation for this phenomena will be advanced. It should be noted that dichotomizing the density regimes at the 0.75 or less level, taking a weighted average of the percentages of each density regime half, and utilizing differences of proportions to analyze the differences results in a z-score of only 0.5 (significant at the 0.3085 level). On this basis, it appears that the relationship which seems to be manifesting itself is not due to any 
pattern, but rather due to chance.

Rather than dismiss the hypothesis that increased density is related to stress-related morbidities, it is possible to investigate the implications of Table II and Table III further by taking another approach. Table IV lists the deviation ratios of all stress-related morbidities examined in this thesis.

From Table IV, it is evident that all stress-related morbidities do not follow a consistent pattern across all levels of density. However, individual morbidity categories, in many cases, do follow a definite trend. Those that follow the hypothesized pattern of greater relative incidence of morbidity being generally associated with higher levels of density are quite evident. Common viral infections, endocrine disorders, diseases of nerves and peripheral ganglia, disorders of the digestive system, genito-urinary problems, and morbidities of the female genitals all follow this basic hypothesized pattern. For all these, overrepresentation in the upper regions of density and underrepresentation in the lower regimes is a prevailing pattern. This pattern is termed the "high" pattern, indicating an overrepresentation of morbidities in the regimes of higher density.

A second pattern found is that in which the overrepresented cells are found in the lower range of densities, and in which there is a general negative relationship between increases in density and the deviation ratio value. This pattern is termed the "low" pattern, indicating that the overloaded cells are found in the lower density regimes. From Table IV, note that two morbidity categories follow this pattern: allergies, and rheumatic fever and heart disease. 
A third general pattern is found with those morbidity categories that are overloaded in both the regions of low density and those of high density, but are underloaded in the regimes of medium densities. This pattern is termed the " $u$ " shaped loading pattern. Only one morbidity category falls clearly into this pattern; that of obesity.

TABLE IV

DEVIATION RATIOS OF STRESS-RELATED MORBIDITY

CATEGORIES ACROSS DENSITY REGIMES

Density Regime

\begin{tabular}{|c|c|c|c|c|c|c|c|}
\hline $\begin{array}{l}\text { Morbidity } \\
\text { Category }\end{array}$ & $\begin{array}{c}\text { Less than } \\
0.26 \\
\end{array}$ & $\begin{array}{l}0.26 \text { to } \\
0.50 \\
\end{array}$ & $\begin{array}{l}0.51 \text { to } \\
0.75 \\
\end{array}$ & $\begin{array}{l}0.76 \text { to } \\
1.00\end{array}$ & $\begin{array}{c}1.01 \text { to } \\
1.50\end{array}$ & $\begin{array}{c}1.51 \text { to } \\
2.00\end{array}$ & $\begin{array}{l}\text { More } \\
\text { than } \\
2.00 \\
\end{array}$ \\
\hline Common Viral & 0.888 & 0.921 & 1.363 & 1.037 & $-\star$ & - & - \\
\hline Allergies & 1.908 & 0.965 & 0.701 & 0.888 & - & - & - \\
\hline Endocrine & 0.996 & 0.947 & 1.260 & 1.009 & - & - & - \\
\hline Obesity & 1.336 & 0.921 & 0.409 & 1.561 & $4.368 * \star$ & - & - \\
\hline Emotional & 1.048 & 0.838 & 1.279 & 0.813 & 2.272 & - & $2.200 * \star$ \\
\hline $\begin{array}{l}\text { Nerves and } \\
\text { Ganglia }\end{array}$ & 0.872 & 0.947 & 0.765 & 1.318 & 3.316 & - & - \\
\hline $\begin{array}{l}\text { Rheu. Fever, } \\
\text { Heart Dis. }\end{array}$ & 1.200 & 1.166 & 0.775 & 0.439 & 0.524 & - & 0.100 \\
\hline $\begin{array}{l}\text { Arteries and } \\
\text { Veins }\end{array}$ & 1.100 & 0.948 & 1.122 & 0.925 & 0.940 & 1.500 & - \\
\hline $\begin{array}{l}\text { Digestive } \\
\text { System }\end{array}$ & 0.888 & 0.969 & 1.103 & 1.094 & 1.048 & $0.500 * *$ & 1.797 \\
\hline $\begin{array}{l}\text { Genito } \\
\text { Urinary }\end{array}$ & 0.720 & 1.107 & 0.848 & 1.009 & 1.149 & 3.000 & - \\
\hline $\begin{array}{l}\text { Females } \\
\text { Genitals }\end{array}$ & 0.560 & 0.724 & 1.520 & 1.764 & 2.038 & - & - \\
\hline $\begin{array}{l}\text { *indicates } \mathrm{ce} \\
\star \star \text { indicates } \mathrm{r} \\
\end{array}$ & $\begin{array}{l}\text { ell frequen } \\
\text { catio based }\end{array}$ & $\begin{array}{l}\text { hey of ze } \\
\text { on cell }\end{array}$ & $\begin{array}{l}\text { ero } \\
1 \text { frequen }\end{array}$ & $2 c y$ of on & e & & \\
\hline
\end{tabular}


The fourth pattern which is indicated is, in a sense, no pattern at all, since the overloaded cells are found across the range of density regimes. Into this pattern fall both emotional disturbances and diseases of the arteries and veins. Both are overloaded in the lowest density regime, underloaded in the next, overloaded in the "0.51 to $0.75^{\prime \prime}$ regime, and underloaded in the following regime. Beyond this point, the mutuality of the pattern is not found, with emotional disturbances rising in the "1.01 to $1.50 "$ regime, while diseases of the arteries and veins continue to be underloaded in the same density regime. However, emotional disturbances continues high in the following regimes, while diseases of the arteries and veins rises to an overloaded position in the $" 1.51$ to $2.00 "$ range. This pattern of alternate overloaded and underloaded cells is termed the oscillating pattern. Thus four basic patterns emerge across density regimes in those morbidities typified as stress-related. It is interesting to note that all disease categories with probable stress components do not follow the same pattern. For example, stress has been found to be a component of both genito-urinary morbidities and heart disease (Dodge, unpubIished article; French and Caplan, 1974). Despite this, genito-urinary morbidities are positively related to density (the "high" pattern) while heart disease is negatively related (the "low" pattern). In addition, there seems to be no common quality between morbidities found in the same pattern. For example, there seems to be little in common between heart disease and allergies, yet they follow the same pattern. Those morbidities that might be physiologically related may follow different patterns. Again using heart disease as an example, we note that 
it follows a "low" pattern, while morbidities of the arteries and veins, which can in some cases be linked to arterio-coronary problems, follow an oscillating pattern.

To further examine this problem, the deviation ratios of those morbidities typified as non-stress related are listed in Table $V$. Beginning with the "high" pattern morbidities, note that only two diseases fall into this pattern: micro-organisms and diseases of the bones, muscles, and joints. Although the latter category drops to 1.000 in the " 1.51 to 2.00 " density regime, the ratio is based on a cell frequency of one only, and thus should probably be disregarded. In the "low" pattern are found malignant neoplasms, eye diseases and morbidities of the respiratory system. The "U" pattern contains venereal disease, morbidities of the central nervous system, ear diseases, and trauma and burns. The "oscillating" pattern includes anemias and blood diseases, and skin morbidities. Interestingly, a new pattern is found in Table $V$ which does not appear in the stress-related morbidities of Table IV: that of the "hump" pattern, characterized by underloadings on either density extreme and overloadings in the middle density regimes. Only one morbidity follows this pattern clearly: non-neoplastic breast disorders. Benign neoplasms follow the "high" pattern through the "0.76 to 1.00 " density regime, but present the "U" pattern beyond the " 1.00 " density level.

The percentages of patterns found in each type of morbidity as indicated in Tables IV and $V$ are summarized in Table VI. In analyzing the data two approaches have been utilized. First, using the matched pairs technique, we find a difference between the two morbidity 
TABLE V

DEVIATION RATIOS OF NON-STRESS RELATED

MORBIDITY CATEGORIES, ACROSS

DENSITY REGIME

\begin{tabular}{|c|c|c|c|c|c|c|c|}
\hline \multicolumn{8}{|c|}{ Density Regime } \\
\hline $\begin{array}{l}\text { Morbidity } \\
\text { Category }\end{array}$ & $\begin{array}{c}0.0 \text { to } \\
0.25\end{array}$ & $\begin{array}{l}0.26 \text { to } \\
0.50\end{array}$ & $\begin{array}{l}0.51 \text { to } \\
0.75\end{array}$ & $\begin{array}{l}0.76 \text { to } \\
1.00\end{array}$ & $\begin{array}{l}1.01 \text { to } \\
1.50\end{array}$ & $\begin{array}{l}1.51 \text { to } \\
2.00 \\
\end{array}$ & $\begin{array}{c}\text { More than } \\
2.00 \\
\end{array}$ \\
\hline Veneral & & & & & & & \\
\hline Disease & 2.264 & 0.611 & 1.630 & $-*$ & - & - & - \\
\hline $\begin{array}{l}\text { Micro- } \\
\text { organisms }\end{array}$ & 0.693 & 0.769 & 1.608 & 1.615 & - & - & - \\
\hline $\begin{array}{l}\text { Malignant } \\
\text { Neoplasm }\end{array}$ & 1.032 & 1.225 & 0.618 & 0.664 & 0.470 & - & - \\
\hline $\begin{array}{l}\text { Benign } \\
\text { Neoplasm }\end{array}$ & 0.752 & 0.801 & 1.856 & 1.477 & 0.834 & 3.000 & - \\
\hline $\begin{array}{l}\text { Anemia and } \\
\text { Related }\end{array}$ & 1.424 & 0.900 & 1.309 & 0.626 & - & - & - \\
\hline $\begin{array}{l}\text { Central ner- } \\
\text { vous system }\end{array}$ & 1.416 & 1.078 & 0.760 & 0.407 & 1.526 & - & - \\
\hline $\begin{array}{l}\text { Eye } \\
\text { Diseases }\end{array}$ & 1.040 & 1.236 & 0.637 & -.636 & - & - & - \\
\hline $\begin{array}{l}\text { Ear } \\
\text { Diseases }\end{array}$ & 1.352 & 0.890 & 0.662 & 1.579 & 1.789 & $5.000 *$ & - \\
\hline $\begin{array}{l}\text { Respiratory } \\
\text { System }\end{array}$ & 1.080 & 1.018 & 1.010 & 0.854 & 0.786 & - & - \\
\hline $\begin{array}{l}\text { Breast, non- } \\
\text { neoplastic }\end{array}$ & 0.424 & 0.873 & 1.804 & 0.981 & - & - & - \\
\hline $\begin{array}{l}\text { Skin } \\
\text { Diseases }\end{array}$ & 0.345 & 0.980 & 1.356 & 0.991 & 2.272 & - & - \\
\hline $\begin{array}{l}\text { Bones, muscl } \\
\text { joints }\end{array}$ & $\begin{array}{l}\text { Les, } \\
0.824\end{array}$ & 0.853 & 1.235 & 1.439 & 1.363 & $1.000 \star \star$ & - \\
\hline $\begin{array}{l}\text { Trauna and } \\
\text { Burns }\end{array}$ & 1.161 & 0.897 & 0.956 & 1.327 & 1.311 & 2.500 & - \\
\hline
\end{tabular}


categories as being significant at the 0.11 level. Examining the differences in percentages within each pattern and across morbidity categories, and utilizing differences of proportions as a measure, some relationships of greater significance are found. Looking first at the " $U$ " pattern, the difference in proportions is significant at the 0.0132 level. On the other hand, the "low" pattern percentage differences and those of the "oscillating" pattern are not statistically significant. The "high" pattern percentage differences, however, are significant at the 0.0212 level.

TABLE VI

PERCENTAGE OF DEVIATION RATIO PATTERNS OCCURRING IN EACH MORBIDITY TYPE

\begin{tabular}{|c|c|c|c|c|c|c|c|}
\hline \multirow[b]{2}{*}{$\begin{array}{l}\text { Morbidity } \\
\text { Type }\end{array}$} & & & & & & & \\
\hline & $\mathrm{U}$ & Low & High & 0 & Hump & Total & Base $\mathrm{N}$ \\
\hline \multicolumn{8}{|l|}{ Stress- } \\
\hline Related & 9.18 & 18.2 & 54.5 & 18.2 & 0.0 & 100.08 & 11 \\
\hline \multicolumn{8}{|l|}{ Non-Stress } \\
\hline Related & 30.8 & 23.1 & 15.4 & 15.4 & 15.4 & $100.08 *$ & 13 \\
\hline
\end{tabular}

One of the most striking aspects of the above significance levels is found in the differences in the percentages in the "high" pattern. Note from Table VI that 54.5 percent of all stress-related morbidities fall into this pattern, while only 15.4 percent of the non-stress related diseases are found in this configuration. The significance level (0.0212) lends some credence to the fundamental assertion of this paper: that stress-related morbidities are associated with higher levels of population density, at least more so than non-stress related diseases. However, in examing Table VI further, it is evident that the "low" 
pattern seems to have little differential association with either morbidity type. Nevertheless, the "U" pattern, which includes the low range of density as well as the upper regimes, does indicate a significant difference, being significantly higher in the non-stress related morbidity type.

A summary of what has been found to this point in the analysis is in order. First, morbidity categories do not follow a general pattern of underloading or overloading across increasing density regimes. Although morbidities with probable stress components do seem to be associated with density, the association is not always in a consistent direction. However, if the various kinds of patterns are examined relative to their association with disease types, significant relationships do emerge. From Table VI and the preceeding discussions, it was found that the "U." pattern is significantly more frequent among non-stress related morbidities, while stress-related morbidities show a significantly greater proportion with the "high" pattern. As discussed in Chapter II, there is some evidence from the literature to support the findings that a median range of density, as indicated by the "U" shaped pattern may be less stressful, while the significance of the "high" pattern for the stress-related morbidity type gives some support to this paper's hypothesis that higher density is more stressful than is lower density, and is more closely associated with stress-related morbidity occurrence.

Before leaving this line of analysis, let us turn to strength of relationship tests between density regimes and the deviation ratios of categories of morbidities. The interest here is in examining whether specific morbidity categories show a general monotonic increase or 
monotonic decrease with increasing density. The linear constraint on the Pearsonian correlation provides the desired indication. By using the midpoints of each density regime as an interval level of measurement, and the deviation ratios as the other interval level of measurement, Pearsonian correlations were generated which give some additional indication of the general direction of relationships, and the correlation coefficients are produced as a measure of the degree to which morbidity occurrence, as measured by the deviation ratio, increases or decreases as a function of density. Table VII sets forth the zero order correlations between density regime midpoints and the deviation ratios of morbidity categories. The primary purpose of this approach is to gain confirmation of the general direction of the relationships, and not with the specific values of the coefficients.

TABLE VII

\section{ZERO ORDER CORRELATIONS BETWEEN DENSITY REGIME MIDPOINTS AND THE DEVIATION RATIOS \\ OF MORBIDITY CATEGORIES}

\section{Negative Correlations}

\begin{tabular}{|c|c|c|}
\hline $\begin{array}{l}\text { Morbidity } \\
\text { Category }\end{array}$ & $\begin{array}{l}\text { Morbidity } \\
\text { Type }\end{array}$ & $\begin{array}{l}\text { Correlation } \\
\text { Coefficients }\end{array}$ \\
\hline Respiratory System & Non-stress & -0.964 \\
\hline Eyes & Non-stress & -0.916 \\
\hline Anemia and Related & Non-stress & -0.885 \\
\hline Malignant Neoplasm & Non-stress & -0.844 \\
\hline Venereal Disease & Non-stress & -0.796 \\
\hline Breast, Non-neo. & Non-stress & -0.245 \\
\hline Micro-organisms & Non-stress & -0.212 \\
\hline Central Nerv. Sys. & Non-stress & -0.061 \\
\hline Allergies & Stress & -0.907 \\
\hline Heart and Related & Stress & -0.779 \\
\hline Endocrine & Stress & -0.693 \\
\hline Common Viral & Stress & -0.589 \\
\hline & $\begin{aligned} \text { Non-Stress } \mathrm{N} & =1524 \\
\text { Stress } \mathrm{N} & =\frac{986}{2510} \\
\text { Total } \mathrm{N} & =1\end{aligned}$ & \\
\hline
\end{tabular}


TABLE VII

(continued)

\section{POSITIVE CORRELATIONS}

Morbidity
Category
Benign Neoplasm
Ears
Burns and Trauma
Bone, Joint, Muscle
Skin
Arteries and Veins
Genito-urinary
Emotional
Digestive System
Obesity
Nerves and Ganglia
Female Genitals

$\begin{aligned} & \text { Morbidity } \\ & \text { Type }\end{aligned}$
Non-stress
Non-stress
Non-stress
Non-stress
Non-stress
Stress
Stress
Stress
Stress
Stress
Stress
Stress
Non-Stress N $=1617$
Stress N $=\frac{2200}{3817}$
Total N

Correlation

Coefficients

0.195

0.559

0.595

0.883

0.892

0.575

0.675

0.699

0.719

0.745

0.830

0.956

Stress $N=\frac{2200}{3817}$

The data in Table VII can be more easily analyzed if they are broken down into more inclusive categories. In Table VIII, the categories have been collapsed into correlation signs (positive or negative), while keeping the distinction between morbidity types. The number of morbidities falling into each cell are indicated.

From Table VII it is evident that the distribution of morbidity types relative to the sign of the correlation coefficients is not significant enough to warrant any general conclusion as to the relationship. Therefore, high correlations not withstanding, it is evident that no pattern can be inferred using correlation coefficients as a measure of the direction of linear relationships.

This finding must be interpreted in the light of the previously mentioned assumption of linearity of relationship. If the grouping of 
morbidity types by correlation signs does not produce a significant difference, between morbidity types, one possible reason may be that all the relationships in question are not linear, but follow some other pattern that is not a monotonic increase or decrease, and thus is inadequately described by a linear function.

TABLE VIII

COMPARISON OF THE NUMBER OF MORBIDITY CATEGORIES OCCURRING IN EACH GROUP OF CORRELATION SIGNS

BY MORBIDITY TYPE, AS LISTED IN

TABLE VII

Morbidity

Sign of Correlation Coefficient

Type Positive Negative Total

Stress-Related 7 4 11

Non-Stress Related 5 8 13

Totals 12 12 24

Chi Square $=1.511, \mathrm{df}=1$

Level of Significance $=0.200$

\section{CONTROLLED RELATIONSHIPS}

\section{Socioeconomic status}

Up to this point in the discussion, only uncontrolled relationships have been examined. Attention is now turned to the control variables to examine their effect on morbidity type/density relationships. Table IX begins this process by setting forth stress-type morbidity occurrence across density regimes, by socioeconomic status. The figures presented are the deviation ratios, to provide a basis of comparison between both the preceding tables and those to follow. 
TABLE IX

DEVIATION RATIOS OF STRESS-RELATED MORBIDITIES

BY DENSITY REGIMES AND SOCIOECONOMIC

STATUS

\begin{tabular}{lcccccc} 
& \multicolumn{6}{c}{ Density Regime } \\
\cline { 2 - 6 } $\begin{array}{l}\text { Socioeconomic } \\
\text { Status }\end{array}$ & $\begin{array}{c}\text { Less than } \\
0.26\end{array}$ & $\begin{array}{c}0.26 \\
0.50\end{array}$ & $\begin{array}{c}0.51 \text { to } \\
0.75\end{array}$ & $\begin{array}{c}0.76 \\
1.00\end{array}$ & $\begin{array}{c}\text { Greater } \\
\text { than } 1.00\end{array}$ \\
\hline Lower & 0.985 & 1.021 & 0.995 & 0.920 & 1.000 \\
\hline Middle & 1.000 & 0.953 & 1.072 & 1.018 & 1.217 \\
\hline & 1.173 & 0.998 & 0.986 & 0.850 & 1.750 \\
\hline
\end{tabular}

$\mathrm{N}=2079$

In analyzing Table IX, note first that the ratios of the lower class follow an oscillating pattern, with the largest deviation occurring in the " 0.76 to 1.00 " regime, and in a negative (underloaded) direction. In general, the middle class follows the "high" pattern, with all the overloaded cells occurring in the upper regions of density. The upper class, however, clearly follows the "U" pattern, with substantial differences occurring in three of the five cells.

To place the relationships in a different perspective, the mode of analysis is now shifted from deviation ratios to that afforded by chi square and Tau B. Table X presents the occurrence of stress and non-stress related morbidities across density regimes for the three socioeconomic classes.

The significance level for the lower class is sufficiently high to warrant a cautious assertion that the type of morbidity occurrence is associated with density regimes. However, the strength of the relationship is obviously quite weak, as indicated by the value of only 0.02 of Kendall's Tau B. A proportionate reduction of errors of only 
TABLE $X$

OCCURRENCE OF MORBIDITY TYPES ACROSS

DENSITY REGIMES BY LEVELS OF SOCIOECONOMIC STATUS

LOW SOCIOECONOMIC STATUS

\begin{tabular}{lccccccc}
\hline \multicolumn{7}{c}{ Density Regime } \\
$\begin{array}{l}\text { Morbidity } \\
\text { Type }\end{array}$ & $\begin{array}{c}\text { Less than } \\
0.26\end{array}$ & $\begin{array}{c}0.26 \\
0.50\end{array}$ & $\begin{array}{c}0.51 \text { to } \\
0.75\end{array}$ & $\begin{array}{c}0.76 \\
1.00\end{array}$ & $\begin{array}{c}\text { Greater } \\
\text { than } 1.00\end{array}$ \\
\hline $\begin{array}{l}\text { Stress- } \\
\text { Related }\end{array}$ & 106 & 960 & 144 & 189 & 44 & 1643 \\
\hline $\begin{array}{l}\text { Non-Stress } \\
\text { Related }\end{array}$ & 105 & 863 & 327 & 210 & 41 & 1546 \\
\hline & 211 & 1823 & 671 & 399 & 85 & 3189 \\
\hline
\end{tabular}

Chi Square $=10.967$, df $=4$

Tau $B=0.0200$

Level of Significance $=0.0894$

MIDDLE SOCIOECONOMIC STATUS

\begin{tabular}{lccccccc}
\hline \multicolumn{7}{c}{ Density Regime } \\
$\begin{array}{l}\text { Morbidity } \\
\text { Type }\end{array}$ & $\begin{array}{c}\text { Less than } \\
0.26\end{array}$ & $\begin{array}{c}0.26 \\
0.50\end{array}$ & $\begin{array}{c}0.51 \text { to } \\
0.75\end{array}$ & $\begin{array}{c}0.76 \\
1.00\end{array}$ & $\begin{array}{c}\text { Greater } \\
\text { than } 1.00\end{array}$ & $\begin{array}{c}\text { Total } \\
\text { Stress- }\end{array}$ \\
$\begin{array}{l}\text { Related } \\
\text { Non-Stress }\end{array}$ & 22 & 145 & 82 & 32 & 8 & 289 \\
\hline $\begin{array}{l}\text { Related } \\
\text { Totals }\end{array}$ & 22 & 159 & 71 & 31 & 5 & 288 \\
\hline
\end{tabular}

Chi Square $=2.142$, df $=4$

Level of Significance $=0.7097$

Tau $B=0.047$

HIGH SOCIOECONOMIC STATUS

\begin{tabular}{|c|c|c|c|c|c|c|}
\hline \multicolumn{7}{|c|}{ Density Regime } \\
\hline $\begin{array}{l}\text { Morbidity } \\
\text { Type }\end{array}$ & $\begin{array}{l}\text { Iess than } \\
0.26\end{array}$ & $\begin{array}{c}0.26 \text { to } \\
0.50\end{array}$ & $\begin{array}{l}0.51 \text { to } \\
0.75\end{array}$ & $\begin{array}{c}0.76 \text { to } \\
1.00\end{array}$ & $\begin{array}{l}\text { Greater } \\
\text { than } 1.00\end{array}$ & Total \\
\hline Stress- & & & & & & \\
\hline Related & 19 & 70 & 42 & 15 & 1 & 147 \\
\hline $\begin{array}{l}\text { Non-Stress } \\
\text { Related }\end{array}$ & 12 & 65 & 40 & 19 & 0 & 136 \\
\hline Totals & 31 & 135 & 82 & 34 & 1 & 283 \\
\hline
\end{tabular}

Chi Square $=2.862, \mathrm{df}=4$

Tau $B=0.057$

Level of Significance $=0.5812$ 
2 percent cannot be regarded as possessing sufficient strength to be regarded as important.

In examining the level of significance for both middle and high socioeconomic status patients, it is evident that there is no relationship between morbidity type and density regime. However, by referring again to Table IX, it can be noted that the distribution of stressrelated morbidities for the middle class follows a high pattern of overloading, consistent enough with a variety of other morbidities to indicate that the same type of pattern is emerging.

Returning again to Table IX, note that the upper class pattern of deviation ratios follows a "U" shaped form, although it is evident that the region of greatest deviation, that of the density regime "Greater than 1.00" is based on only l patient (Table X).

In summary, the effect of middle or upper social class on the relationship between morbidity type occurrence and density is found to be either none, or minimal at best. For the lower class such a relationship is found, but the strength of the relationship is quite weak.

Age

Turning to an examination of the impact of age categories on morbidity type occurrence across density regimes as a starting point of this investigation, a consideration of the deviation ratios of stressrelated morbidities across density regimes, by age cohorts is in order. (See Table XI). 
TABLE XI

\section{DEVIATION RATIOS OF STRESS-RELATED MORBIDITIES ACROSS DENSITY REGIMES,} BY AGE COHORTS

\begin{tabular}{lcccccc}
$\begin{array}{l}\text { Age } \\
\text { Cohort }\end{array}$ & $\begin{array}{c}\text { Less than } \\
0.26\end{array}$ & $\begin{array}{c}0.26 \text { to } \\
0.50\end{array}$ & $\begin{array}{c}0.51 \text { to } \\
0.75\end{array}$ & $\begin{array}{c}0.76 \\
1.00\end{array}$ & $\begin{array}{c}\text { Greater } \\
\text { than } 1.00\end{array}$ \\
\hline $\begin{array}{l}\text { Young } \\
\text { Adult }\end{array}$ & 0.764 & 0.926 & 1.062 & 1.115 & 0.793 \\
\hline $\begin{array}{l}\text { Mature } \\
\text { Adult }\end{array}$ & 0.943 & 1.025 & 1.004 & 0.913 & 1.111 \\
\hline $\begin{array}{l}\text { Elderly } \\
\text { Adult }\end{array}$ & 0.975 & 1.000 & 1.127 & 0.773 & 1.333 \\
\hline
\end{tabular}

The patterns that emerge from Table XI are not particularly clear cut. Nevertheless, some general tendencies can be noted. Looking first at the regime of density "Greater than 1.00 " persons per room, observe that both the mature adult and the elderly adult categories are overloaded. This is especially noticeable in the elderly adult cohort. The young adult cohort, on the other hand, is clearly underloaded in this density regime. This may indicate some small degree of support for one of the concepts underlying the hypothesis of this paper; namely, that younger persons are more adaptable, and may find high density circumstances less stressful. It is also noteworthy that such a between-cohort distribution pattern occurs only in the "Greater than 1.00 " regime.

It may be recalled from Chapter II that it was suggested that more than one person per room could create a series of situations where internal escape space was not available due to distributions of other persons throughout the available rooms, thus precluding relief from stress engendered by interpersonal conflict, exacerbated by population press. 
Another characteristic that all cohorts have in common is the overloading in the " 0.51 to 0.75 " density regime, with the greatest degree of overloading occurring in the elderly adult cohort. In addition, the regime of lowest density is underloaded across all three cohorts, with the range of lowest to highest running from young adult at 0.764 deviation ratio to elderly adult at 0.975 , with the mature adult cohort falling in the middle at 0.943 .

In examining the general pattern type of the deviation ratios of Table XI, note that the young adult cohort follows a general "high" pattern, if the latter density regime of "greater than $1.00 "$ is ignored (it contains only 2.3 percent of the total cohort observations). The mature adult cohort follows the oscillating pattern, while that of the elderly adult follows the "hump" pattern. It would appear from the patterns that higher density is more associated with stress-related morbidities in the young adult cohort, while the median range of density is more associated with the occurrence of stress-related morbidities in the elderly.

To provide a comparative measure of the amount of variation from the expected deviation ratio value of 1.000 , and since conventional variance analysis cannot be used (given that the data are not derived from independent random samples), the problem can be approached by looking at the mean average of the sum of the differences from the expected value of 1.000 across each density regime, and within each age cohort. Table XII indicates the results of each computation. 
TABLE XII

WEIGHTED MEAN AVERAGE OF THE DIFFERENCES BETWEEN DEVIATION

RATIOS AND EXPECTED VALUE OF 1.000 ACROSS

DENSITY REGIMES, BY AGE COHORT

Age Cohort

Young Adult

Mature Adult

Elderly Adult

$\mathbf{N}=3186$

\section{Mean Difference}

0.089

0.034

0.021

Note that the young adult cohort has the largest mean difference, whereas the elderly adult cohort has the smallest value. This should not be entirely unexpected if adaptability is learned. This seems to stand in opposition to some of the previous findings, however. The analysis of Table XI indicated that the younger adults may be more, not less adaptable. It should also be noted that the widest variation noted in the elderly adult cohort - that of 0.333 found in the "Greater than 1.00" density regime - is based on only five patients (See Table XI), whereas the region of wide variation in the young adult cohort is based on larger numbers of observations.

Turning to the more traditional measures of relationship, Table XIII sets forth the frequencies of stress and non-stress related morbidities across density regimes, by age cohort.

From the significance levels, it would appear that density is related to the occurrence of morbidity type within all age cohorts. In none of the age cohorts, however, is the relationship strong, as measured by Tau B. In view of this, it must be presumed at this point that the significance levels are due to the large numbers of observations, rather than reflecting strong relationships. 
TABLE XIII

OCCURRENCE OF MORBIDITY TYPES ACROSS

DENSITY REGIMES BY

AGE COHORT

YOUNG ADULT AGE COHORT

\begin{tabular}{lccccccc}
\hline & \multicolumn{7}{c}{ Density Regime } \\
\cline { 2 - 7 } $\begin{array}{l}\text { Morbidity } \\
\text { Type }\end{array}$ & $\begin{array}{c}\text { Less than } \\
0.26\end{array}$ & $\begin{array}{c}0.26 \\
0.50\end{array}$ & $\begin{array}{c}0.51 \\
0.75\end{array}$ & $\begin{array}{c}0.76 \\
1.00\end{array}$ & $\begin{array}{c}\text { to } \\
\text { than } 1.00\end{array}$ & Total \\
\hline $\begin{array}{l}\text { Stress- } \\
\text { Related }\end{array}$ & 24 & 187 & 215 & 133 & 13 & 572 \\
\hline $\begin{array}{l}\text { Non-Stress } \\
\text { Related }\end{array}$ & 50 & 472 & 474 & 280 & 26 & 767 \\
\hline & 74 & 659 & 689 & 413 & 39 & 1339 \\
\hline
\end{tabular}

Chi Square $=116.059$

Level of Significance $=.0001$

Tau $B=0.060$

$\mathrm{df}=4$

MATURE ADULT AGE COHORT

\begin{tabular}{|c|c|c|c|c|c|c|}
\hline \multicolumn{7}{|c|}{ Density Regime } \\
\hline $\begin{array}{l}\text { Morbidity } \\
\text { Type } \\
\end{array}$ & $\begin{array}{c}\text { Less than } \\
0.26 \\
\end{array}$ & $\begin{array}{c}0.26 \text { to } \\
0.50\end{array}$ & $\begin{array}{l}0.51 \text { to } \\
0.75\end{array}$ & $\begin{array}{c}0.76 \text { to } \\
1.00\end{array}$ & $\begin{array}{l}\text { Greater } \\
\text { than } 1.00\end{array}$ & Total \\
\hline Stress- & & & & & & \\
\hline Related & 106 & 642 & 326 & 162 & 15 & 1287 \\
\hline Non-Stress & & & & & & \\
\hline Related & 106 & 547 & 239 & 175 & 32 & 1154 \\
\hline Totals & 212 & 1189 & 615 & 337 & 79 & 2441 \\
\hline
\end{tabular}

Chi Square $=11.050$

Level of Significance $=.005$

Tau $B=0.01$

$\mathrm{df}=4$

ELDERLY ADULT AGE COHORT

\begin{tabular}{lccccccc}
\hline & \multicolumn{8}{c}{ Density Regime } \\
\cline { 2 - 8 } $\begin{array}{l}\text { Morbidity } \\
\text { Type }\end{array}$ & $\begin{array}{c}\text { Less than } \\
0.26\end{array}$ & $\begin{array}{c}0.26 \text { to } \\
0.50\end{array}$ & $\begin{array}{c}0.51 \text { to } \\
0.75\end{array}$ & $\begin{array}{c}0.76 \\
1.00\end{array}$ & $\begin{array}{c}\text { Greater } \\
\text { than } 1.00\end{array}$ & Total \\
\hline $\begin{array}{l}\text { Stress- } \\
\text { Related }\end{array}$ & 255 & 026 & 118 & 23 & 5 & 1327 \\
\hline $\begin{array}{l}\text { Non-Stress } \\
\text { Related }\end{array}$ & 248 & 851 & 84 & 34 & 3 & 1220 \\
\hline Totals & 503 & 1777 & 202 & 57 & 8 & 2547 \\
\hline
\end{tabular}

Chi Square $=7.128$

Level of Significance $=.100$

Tau $B=0.02$

$\mathrm{df}=4$ 
Table XIII has indicated that age has some influence on the morbidity type/ density regime relationship. It is also possible to examine relationships between age cohort and density regimes, given that the patient has contracted a stress-related morbidity. Table XIV sets forth this data for stress-related morbidities only, by density regime and age cohort.

TABLE XIV

STRESS-RELATED MORBIDITY OCCURRENCE BY DENSITY REGIME AND AGE COHORT

\begin{tabular}{|c|c|c|c|c|c|c|}
\hline \multicolumn{7}{|c|}{ Density Regime } \\
\hline $\begin{array}{l}\text { Age } \\
\text { Cohort }\end{array}$ & $\begin{array}{c}\text { Less than } \\
0.26\end{array}$ & $\begin{array}{l}0.26 \text { to } \\
0.50\end{array}$ & $\begin{array}{l}0.51 \text { to } \\
0.75\end{array}$ & $\begin{array}{l}0.76 \text { to } \\
1.00\end{array}$ & $\begin{array}{l}\text { Greater } \\
\text { than } 1.00\end{array}$ & Total \\
\hline \multicolumn{7}{|l|}{ Young } \\
\hline Adult & 24 & 187 & 215 & 133 & 13 & 572 \\
\hline \multicolumn{7}{|l|}{ Mature } \\
\hline Adult & 106 & 642 & 326 & 162 & 51 & 1277 \\
\hline \multicolumn{7}{|l|}{ Elderly } \\
\hline Adult & 255 & 926 & 118 & 23 & 5 & 1327 \\
\hline Totals & 385 & 1755 & 159 & 318 & 69 & 3186 \\
\hline
\end{tabular}

Chi Square $=587.3$, df $=8$

Level of Significance $=$ less than 0.0001

The level of significance indicates that we can assert that there is definitely a relationship between levels of density and age cohort, given the fact that the individual has developed a stress-related morbidity. Later in this chapter, when the variables are dichotomized to develop correlation coefficients, this same relationship emerges as a -0.43 correlation coefficient. The information presented in Table XIV therefore acts as additional support for the later correlational findings.

Social Support

There now remains one additional variable, that of social support. 
The data shown in Table XV reflect the occurrence of morbidity types across density regimes controlling for social support.

TABLE XV

OCCURRENCE OF MORBIDITY TYPES ACROSS

DENSITY REGIMES BY LEVELS

OF SOCIAL SUPPORT

LOW SOCIAL SUPPORT

\begin{tabular}{lccccccc}
\hline & \multicolumn{9}{c}{ Density Regime } & & \\
\cline { 2 - 8 } $\begin{array}{l}\text { Morbidity } \\
\text { Type }\end{array}$ & $\begin{array}{c}\text { Less than } \\
0.26\end{array}$ & $\begin{array}{c}0.26 \text { to } \\
0.50\end{array}$ & $\begin{array}{c}0.51 \text { to } \\
0.75\end{array}$ & $\begin{array}{c}0.76 \\
1.00\end{array}$ & $\begin{array}{c}\text { Greater } \\
\text { than } 1.00\end{array}$ \\
\hline $\begin{array}{l}\text { Stress- } \\
\text { Related }\end{array}$ & 173 & 138 & 24 & 13 & 4 & 352 \\
\hline $\begin{array}{l}\text { Non-Stress } \\
\text { Related }\end{array}$ & 185 & 158 & 30 & 20 & 8 & 401 \\
\hline \begin{tabular}{l} 
Totals \\
\hline
\end{tabular} & 358 & 296 & 54 & 33 & 12 & 753 \\
\hline
\end{tabular}

Chi Square $=2.019$, df $=4$

Tau $B=0.038$

Level of Significance $=.700$

MEDIUM SOCIAL SUPPORT

\begin{tabular}{lccccccc}
\hline & \multicolumn{8}{c}{ Density Regime } \\
$\begin{array}{l}\text { Morbidity } \\
\text { Type }\end{array}$ & $\begin{array}{c}\text { Less than } \\
0.26\end{array}$ & $\begin{array}{c}0.26 \\
0.50\end{array}$ & $\begin{array}{c}0.51 \\
0.75\end{array}$ & $\begin{array}{c}0.76 \\
1.00\end{array}$ & $\begin{array}{c}\text { Greater } \\
\text { than }\end{array}$ & $\begin{array}{l}1.00 \\
\text { Total }\end{array}$ \\
\hline $\begin{array}{l}\text { Stress- } \\
\text { Related }\end{array}$ & 63 & 144 & 56 & 37 & $?$ & 297 \\
\hline $\begin{array}{l}\text { Non-stress } \\
\text { Related }\end{array}$ & 76 & 139 & 75 & 26 & 2 & 318 \\
\hline Totals & 139 & 283 & 131 & 53 & 9 & 615 \\
\hline
\end{tabular}

Chi Square $=11.262$, df $=4$

Tau $B=0.012$

Level of Significance $=.020$

HIGH SOCIAL SUPPORT

\begin{tabular}{lccccccc}
\hline & \multicolumn{8}{c}{ Density Regime } \\
\cline { 2 - 8 } $\begin{array}{l}\text { Morbidity } \\
\text { Type }\end{array}$ & $\begin{array}{c}\text { Less than } \\
0.26\end{array}$ & $\begin{array}{c}0.26 \text { to } \\
0.50\end{array}$ & $\begin{array}{c}0.51 \text { to } \\
0.75\end{array}$ & $\begin{array}{c}0.76 \\
1.00\end{array}$ & $\begin{array}{c}\text { Greater } \\
\text { than } 1.00\end{array}$ & Total \\
\hline $\begin{array}{l}\text { Stress- } \\
\text { Related }\end{array}$ & 14 & 238 & 122 & 52 & 13 & 439 \\
\hline $\begin{array}{l}\text { Non-Stress } \\
\text { Related }\end{array}$ & 15 & 253 & 109 & 77 & 14 & 468 \\
\hline \begin{tabular}{l} 
Totals \\
\hline
\end{tabular} & 29 & 491 & 231 & 129 & 27 & 907 \\
\hline
\end{tabular}

Chi Square $=5.090$, df $=4$

Tau $B=0.017$

Level of Significance $=.300$ 
TABLE XV

(continued)

VERY HIGH SOCIAL SUPPORT

\begin{tabular}{|c|c|c|c|c|c|c|}
\hline \multicolumn{7}{|c|}{ Density Regime } \\
\hline $\begin{array}{l}\text { Morbidity } \\
\text { Type }\end{array}$ & $\begin{array}{l}\text { Less than } \\
0.26\end{array}$ & $\begin{array}{l}0.26 \text { to } \\
0.50\end{array}$ & $\begin{array}{l}0.51 \text { to } \\
0.75\end{array}$ & $\begin{array}{l}0.76 \text { to } \\
1.00\end{array}$ & $\begin{array}{l}\text { Greater } \\
\operatorname{than} 1.00\end{array}$ & Total \\
\hline \multicolumn{7}{|l|}{ Stress- } \\
\hline Related & 57 & 879 & 340 & 184 & 40 & 1500 \\
\hline \multicolumn{7}{|l|}{ Non-Stress } \\
\hline Related & 44 & 767 & 337 & 193 & 32 & 1373 \\
\hline Totals & 101 & 1646 & 677 & 377 & 63 & 2873 \\
\hline
\end{tabular}

Chi Square $=6.142$, df $=4$

Tau $B=0.032$

Level of Significance $=.200$

In examining the significance levels indicated in Table $\mathrm{XV}$ for each social support level, it is evident that no significant relationship appears by controlling for low, high or very high social support. Controlling for medium level social support does produce a level of significance of some import, indicating that some relationship exists. However, the low value of Tau B indicates that such a relationship is extremely weak.

To summarize, only one level of social support, that of the medium level, was found to have any effect on morbidity type occurrence across density regimes. Because the relationship is extremely weak, as measured by Tau B, it should be regarded as generally unimportant.

In addition to the analysis of social support as an intervening or qualifying variable, it is possible to examine the deviation ratios of stress-related morbidities across the various density regimes, by level of social support, to determine if any significant patterns of over or under loadings occur. Table XVI presents this information. 
TABLE XVI

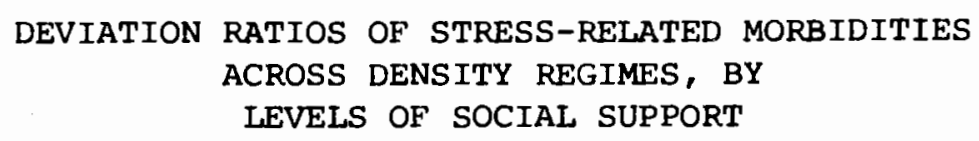

\begin{tabular}{lccccccc} 
& \multicolumn{8}{c}{ Density Regime } \\
\cline { 2 - 7 } $\begin{array}{l}\text { Social } \\
\text { Support }\end{array}$ & $\begin{array}{c}\text { Less than } \\
0.26\end{array}$ & $\begin{array}{c}0.26 \text { to } \\
0.50\end{array}$ & $\begin{array}{c}0.51 \text { to } \\
0.75\end{array}$ & $\begin{array}{c}0.76 \\
1.00\end{array}$ & $\begin{array}{c}\text { Greater } \\
\text { than } 1.00\end{array}$ & Pattern \\
\hline Low & 1.034 & 0.997 & 0.944 & 0.841 & 0.688 & Low \\
\hline Medium & 0.938 & 1.054 & 0.887 & 1.058 & 1.600 & $\begin{array}{c}\text { High } \\
\text { Oscil. }\end{array}$ \\
\hline High & 1.000 & 1.002 & 1.090 & 0.831 & 1.000 & Oscil. \\
\hline $\begin{array}{l}\text { Very } \\
\text { High }\end{array}$ & 1.086 & 1.023 & 0.962 & 0.939 & 1.080 & "U" \\
\hline
\end{tabular}

Total $\mathbf{N}=2588$

of the four levels of social support, that in the low region has the clearest pattern. Note that the low level has a definite low pattern of overloading, with a definite inverse relationship to density. The patterns of the other levels are not as definite. The medium level indicates a tendency to be overloaded towards the upper range of the density continuum, but there is also an overloaded cell in the "0.26 to $0.50 "$ regime, while both the next lower and next higher regimes are underloaded. The high level of social support is clearly an oscillating pattern, with very little deviation from the expected value except in the $" 0.76$ to $1.00 "$ regime. The very high level of social support appears to follow a "U" pattern, although the deviations appear to be minimal. As an explanation of the clear pattern found in the level of low social support, it may be that the sheer presence of others, even non-significant others may serve to mitigate somewhat the hypothesized effects of population press, as long as population density does not exceed some critical limit. The only overloaded cell is found 
in circumstances of very low density, indicating that the patients living in these circumstances are relatively isolated, physically as indicated by the low density regime in which they reside, and socially as indicated by their low level of social support. The two factors combined may account for the overloaded cell occurring in that particular position, as opposed to other levels of density which have their overloaded cells differently distributed.

\section{Analysis of Representative Morbidities}

Up to this point in the analysis, we have been examining morbidity types, which are combinations of several morbidity categories. As may be recalled from Table IV and Table $V$, the patterns of deviation ratios within each type are not consistent, but may in fact load in opposite density regimes. This fact may account, in part, for the singular lack of significant density regime/morbidity type relationships that have been examined in the preceeding pages. To further investigate this problem, it will become necessary to temporarily set aside the operationalization of morbidities into stress-related and non-stress related types and instead examine individual categories of morbidities within each type, as well as across types. It would appear that one of the points to be inferred from Tables IV, V, and VI is that if density is stressful, its effect on morbidity occurrence cannot be inferred by categorization of morbidities into broad types. It should be noted, however, that the stress-related type is considerably more consistent in exhibiting clearly defined patterns than is the non-stress related type.

The pattern distributions from Table IV and Table $\mathrm{V}$ can serve 
as the basis of choosing representative morbidities. Of the eleven morbidities appearing in Table IV, six of them follow the high pattern. Of these six, morbidities of the female genitals follow the most clear pattern across density regimes. In addition, it is of sufficient frequency. that it occurs in nearly all density regimes. Also, its stress component has been fairly well established by prior research (Stokols, 1972; Dodge, unpublished article), and thus could fairly be chosen as representative of stress-related morbidities, in that it follows the modal deviation pattern. From Table V, it can be noted that no clear majority of pattern types of non-stress related morbidities is to be found. Although there are four "U" shaped patterns, the infrequency of venereal disease (total $N=6$ ) renders it unac- . ceptable for our purpose, thus reducing the usable frequency of the "U" pattern to only two. The low pattern is the next most prevalent, and from those three morbidities displaying such a form, that of morbidities of the eye has been chosen on the basis of its probable lack of stress components. Some case could be made for a higher stress component in both the other morbidities present in the "low" pattern (Aakster, 1974; Dodge, unpublished article). Although each of the representative morbidities is the extreme case of deviation ratio patterning, each is nevertheless representative of an "ideal type" found to be most prevalent in each of the morbidity types.

The investigation is best begun by approaching the two ideal morbidity types using traditional measures of association. The levels of significance for these two types of morbidities, with the indicated controls are given in Table XVII. 
In examining Table XVII, note that four types of controls produce levels of significance of 0.10 or less: middle socioeconomic status, mature adult age cohort, high social support, and very high social support. With this table as a guideline, each of these particular controls can be examined in more detail.

TABLE XVII

COMPARISON OF SIGNIFICANCE LEVELS OF "IDEAL TYPE" MORBIDITIES ACROSS DENSITY REGIMES, BY CONTROL VARIABLES

Control

Variable

Socioeconomic

Status

Low

Middle

$\mathrm{High}$

Age Cohort

Young Adult

Mature Adult

Elderly Adult

Social Support

Low

Medium

$\mathrm{High}$

Very High

\section{Chi Square \\ Level of \\ Significance \\ Base N}

$\begin{array}{ccr}20.825 & \text { Less than } 0.001 & 201 \\ 4.465 & 0.300^{*} & 21 \\ \text { Not Applicable**} & - & -\end{array}$

1.205

8.282

0.558

$\begin{array}{cc}0.85^{\star} & 125 \\ \text { Less than } 0.001 & 138 \\ 0.98 & 127\end{array}$

125

127

4.363

6.396

0.30 *

48

10.504

Less than 0.20 *

54

Less than 0.05

68

27.760

157

*Not Significant

**No incidence of morbidities of the female genitals occurs in high socioeconomic status patients in the population under study.

The two "ideal type" morbidities, compared in terms of percentages occurring in each density regime for each of the controlling variables found to be significant at a 0.10 level or less, are displayed in Table XVIII.

First, it can be noted that in the case of stress-related 


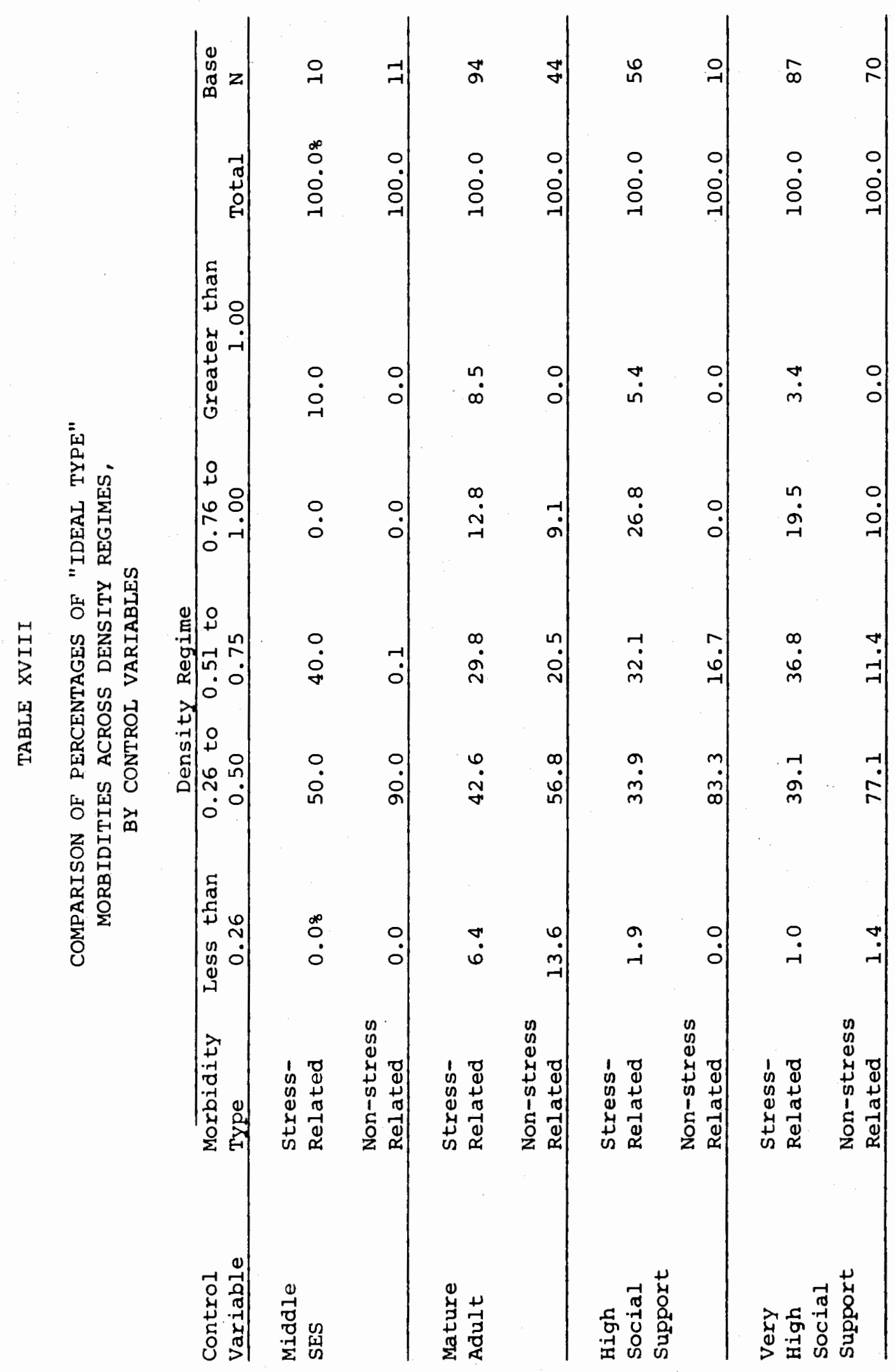


morbidity, some percentages are found in the region of greatest density (greater than 1.00 ) regardless of the controlling variable employed. The occurrence of the non-stress related morbidity tends to be clustered towards the lower or middle range of the density regimes. In no case does the non-stress related morbidity occur in the "greater than 1.00" density regime. In addition, wide differences in percentages appear within the various density regimes.

Rather than simply note the degree of difference, a better approach might be to examine the percentages within each density regime, for each control variable, and, using differences of proportions techniques, evaluate the significance of each set of differences. Table XIX sets forth such significance levels for each density regime, by the controlling variable.

TABLE XIX

SIGNIFICANCE LEVELS FOR DIFFERENCES IN PERCENTAGES OF "IDEAL" MORBIDITY TYPES ACROSS DENSITY REGIMES, BY CONTROL VARIABLES

Density Regime

\begin{tabular}{lccccc}
\hline $\begin{array}{l}\text { Controlling } \\
\text { Variable }\end{array}$ & $\begin{array}{c}\text { Less than } \\
0.26\end{array}$ & $\begin{array}{c}0.26 \text { to } \\
0.50\end{array}$ & $\begin{array}{c}0.51 \text { to } \\
0.75\end{array}$ & $\begin{array}{c}0.76 \\
1.00\end{array}$ & $\begin{array}{c}\text { Greater } \\
\text { than } 1.00\end{array}$ \\
\hline $\begin{array}{l}\text { Middle } \\
\text { SES }\end{array}$ & $\mathrm{N} / \mathrm{A}$ & 0.0192 & 0.0500 & $\mathrm{~N} / \mathrm{A}$ & 0.0001 \\
\hline $\begin{array}{l}\text { Mature } \\
\text { Adult }\end{array}$ & 0.001 & 0.0500 & 0.1271 & $\star$ & 0.0603 \\
$\begin{array}{l}\text { High Social } \\
\text { Support }\end{array}$ & $\star$ & 0.0007 & 0.1515 & 0.0322 & $\star$ \\
$\begin{array}{l}\text { Very High } \\
\text { Social Support }\end{array}$ & $\star$ & 0.0001 & 0.0001 & 0.0537 & 0.0606 \\
\hline
\end{tabular}

*Not significant

All but one of the control variables produce a significant difference in percentages of morbidity types. Both the mature adult 
and the very high social support variables produce a significance at about the same level. It should also be noted that although the direction of occurrence was not anticipated in advance for socioeconomic status, it was hypothesized that high social support would tend to produce a reduction in stress-related morbidities, especially in regimes of high density. By referring to Table XVIII, we note that this is not the case. The non-stress related morbidity has no occurrence in the "greater than 1.00" density regime, while the stressrelated morbidity does occur in that regime, even with very high social support. This finding tends to work against the acceptance of the hypothesis of an inverse relationship of social support and stressrelated morbidity occurrence.

The control variable of middle socioeconomic status produces a significance level of 0.0001 , with the highest percentage occurring in the stress-related region. This is not entirely outside the pale of the hypothesized relationships, in the sense that the occurrence of stress-related morbidities in the regions of higher density was one of the original hypotheses. If density is stressful, then it follows that stress-related morbidities should be disproportionately represented in regions of higher density. However, since only the middle socioeconomic status is represented in Table XIX, it cannot be asserted that the hypothesis is supported, without many qualifications attached to such assertion. This finding of significant differences occurring in only one class may indicate some minor support for the concept that interpretational patterns of the meaning of density are class-specific. Given that the stress-related morbidity has a greater percentage of occurrence than the non-stress related morbidity 
in each of the controlling variable categories in the regime of highest density, it can be observed that stress-related morbidity is significantly associated with middle socioeconomic status, mature adulthood, and very high social support for those patients living in regimes of high density.

Moving to the next lower level of density, that of "0.76 to $1.00 "$ note that only two of the control variables produce any significant differences in the morbidity type distributions. Both high social support and very high social support are associated with significant differences of proportions within that density regime. Referring to Table XVIII, note that in each case the highest percentage of occurrence is in the stress-related category. Therefore it can be concluded that both high and very high social support are more closely associated with stress-related morbidities than with non-stress related morbidities at this level of density. As with the previously discussed density regime, this relationship is the opposite of that anticipated by the hypothesis. If the effect of social support were to reduce density-induced stress, it would be expected that a significantly higher percentage of non-stress morbidities would have been found. It may also be noted that the mature adult control variable produces no significant difference at this density level, although it clearly had an effect in the "greater than 1.00" regime. One explanation for this may be that there is a level of density that is more stressful to those in the mature age cohort. Because each life cycle stage has associated with it its own set of expectations relative to success, achievement, or related factors that find their expression in physical referents such as housing size, this may be a matter of perceived 
status inconsistency, as found by Levy and Herzog (1974). Those in the middle years of life who are living in crowded conditions may be less adaptable than their younger counterparts, with the problem being compounded by life cycle changes, both psychological and physiological, as well as social alterations due to maturing children and increased noise levels within the household. Given that the analysis of Table XVIII indicated that no middle socioeconomic status patients in the study population are found in this density regime, it may be that those mature adults under discussion are either low or high status patients. If in fact they are high status patients, the explanation of status inconsistency takes on added support. If they are low status patients, then the foregoing explanation of other psychosocial factors may be appropriate.

In the "0.51 to $0.75 "$ density regime, only two of the control variables have produced significant differences: those of middle socioeconomic status and very high social support. The significance levels found in the mature adult and high social support variables are not substantial enough to warrant further analysis. The level found in the middle status group is a continuation of the same type of relationship found in the "greater than 1.00 " density regime, with 40 percent of the stress-related morbidity found in this lower regime, as opposed to only 9.1 percent of the non-stress morbidity. Because this difference is significant at the 0.0500 level, it can be cautiously asserted that this level of density is significantly associated with a relatively high occurrence of stress-related morbidities for middle class patients. Why this is so may be explained by the same line of reasoning that was put forth for the difference found in very high density regimes. 
Here, however, the theoretical foundation for the explanation is somewhat more shaky, inasmuch as the data reflect a home environment that allows more than one room per person. "Escape space" therefore exists in this density regime, whereas it does not in the highest density regime. It may well be that some other variable not under analysis is covarying with density to produce this effect at this level of density. The alternative is to assert that this density level is also stressful for patients of middle status, for reasons not included in the theoretical rationale underlying this research.

Very high social support is also closely associated with a significant difference of proportions between morbidity types at this level. Again, the larger of the two percentages is found in the stressrelated category, thus further eroding the hypothesis that higher levels of social support should be associated with proportionately lower percentages of stress-related morbidities.

Moving to the "0.26 to 0.50 " density regime, we find that all control variables reveal significant differences. It should also be noted from Table XVIII that the highest percentage shift from stress to non-stress categories occurs in this density regime. This is not unexpected, in a general sense, as it was hypothesized that stress morbidities are more related to higher levels of density, regardless of control variables employed, and that the lower levels of density should therefore be more closely associated with non-stress morbidities. This pattern is borne out in this density regime, with significant differences occurring across all control categories. It should be noted, however, that the most significant differences occur in the 
categories of high and very high social support. This specific control category further mitigates against the hypothesized relationship of social support and occurrence of morbidity type, since we would be led to believe that the differences should be non-significant at this low density level. This clearly is not the case. Only in the region of extremely low density does the percentage difference cease to be significant.

In the regime of lowest density, only one significant relationship emerges - that of the mature adult category. Here the relationship is in the direction predicted by the hypothesis, with a greater incidence of non-stress related morbidities. This lends some very marginal support to the hypothesized relationship of density and morbidity type occurrence, at least within the mature adult category. It should also be noted that at this level of density, social support as a control produces no significant difference in percentages between the two morbidity categories. This is also in the anticipated direction, for according to expectations, social support should only have an effect at the more stressful higher regimes of density. Thus, there is clearly an effect, but not in the hypothesized direction. Before proceeding to another mode of analysis, a brief summary of the foregoing findings is in order. The "ideal type" stress-related morbidity is found in the hypothesized relationship to density both the middle socioeconomic status and mature adult control categories. In both these control categories, stress-related morbidities are significantly overrepresented in the regimes of high density and significantly underrepresented in the regimes of low density. Applying the 
control variable of high or very high social support re'erses the relationships found in the middle status and mature adult categories, by indicating significant over representation of the stress-related morbidity in the regions of both moderate and high density. The hypothesized relationship between density and morbidity type occurrence is clearly not affected by a high level of social support. Thus the hypothesis that high levels of social support are associated with proportionately low levels of stress-related morbidity is not supported, and must be rejected. It could, in fact, be asserted that high levels of social support are associated with statistically significant disproportionate levels of stress-related morbidities.

As a final statement in this line of analysis, and before moving on to the correlational analysis phase, the deviation ratios across density regimes, as they appear with the other variables acting as controls may be examined. The deviation ratios of the "ideal types" across density regimes for the various levels of the controlling variables are depicted in Table XXI.

The deviation ratios are listed without controls across the top row. Note that both reflect the expected patterns; high in the case of the stress morbidity and low for the non-stress type. Next, notice that the high pattern for the stress-related type holds constant in six of the ten control categories applicable to it. Only in the categories of elderly adult, low social support, and high social support does this dominant pattern disappear. On the other hand, the nonstress morbidity indicates little consistency, with the low pattern of the uncontrolled state being found in only three of the control 
TABLE XX

DEVIATION RATIOS FOR "IDEAL" MORBIDITY TYPES ACROSS DENSITY REGIMES, BY CONTROL VARIABLES

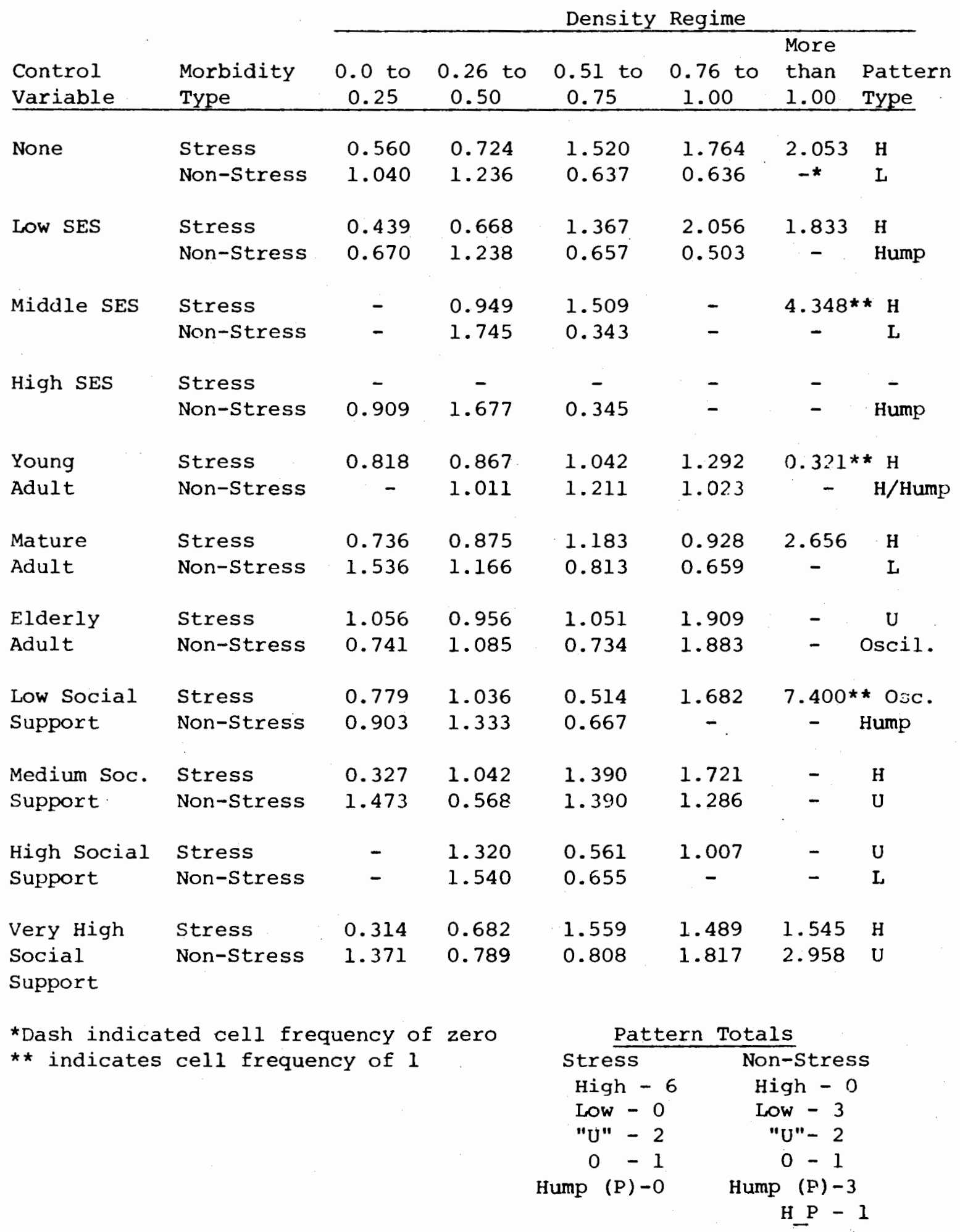


categories, while the hump pattern is found as frequently. Miscellaneous patterns such as the " $U$ " and the "O" are found with equal frequency in each morbidity type, although not always under the same control variable. The principal indication here is that the stressrelated morbidity maintains its relationship to population density much more consistently than does the non-stress related type. Although individual cell values may vary, the pattern is fairly consistent. It might be expected that both morbidity types would fall into an inconsistent pattern for elderly adults. The myriad health problems of the elderly may override or mask any effect of population density as a major causative factor in morbidity development. Whether the onset of degenerative morbidities typical of the elderly is excaberated by environmental stress is an open question. The oscillating pattern of the stress morbidity found in the low social support category has as its lowest point a medium range of density $(0.51$ to 0.75). However, this density regime is not consistently the low point in other oscillating or " $U$ " shaped patterns within other controlling categories. Nevertheless, the only other different pattern for the stress-type morbidity, found in the high social support controlling category, also has its lowest point in this density regime. Whether or not this is significant cannot at this point be determined, but it should be noted as another indication of the general consistency found in the stress-related type, but not in the non-stress related morbidity. 


\section{Correlation and Regression Analysis}

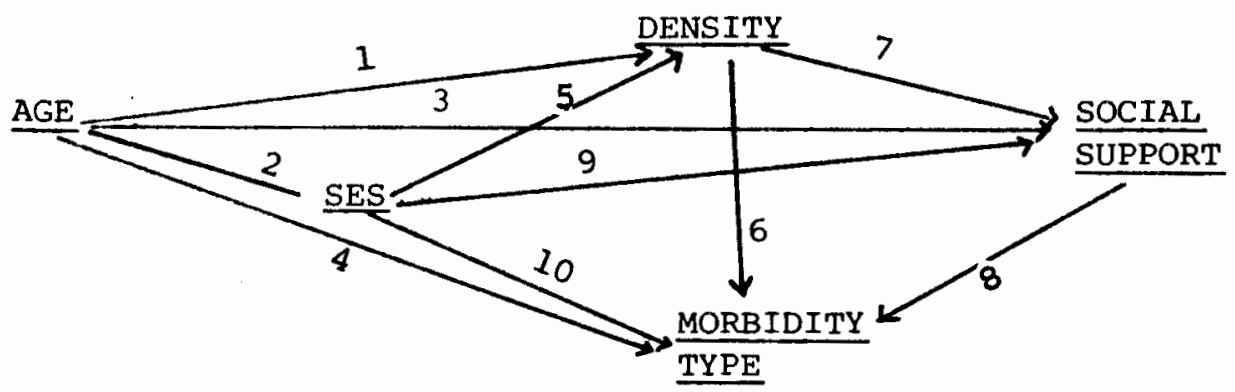

Figure 1. Theoretical causal model of relationships between variables.

Figure 1 sets forth the causal model that includes all possible paths. The rationale that directed the placement of the arrow directions is founded both on logic and theory. First, Age must be regarded as an antecedent variable relative to any of the other four variables. It should be clear that none of these other variables could logically be regarded as a cause of Age. The placement of arrows on paths $1,2,3$, and 4 is dictated by this reasoning. Morbidity type has been regarded as the basic dependent variable throughout this thesis. The methodology was designed to examine the effects of various variables on morbidity type occurrence. Therefore, Age, Density, SES, and Social Support are all regarded as antecedent to Morbidity Type. This reasoning demands the placement of arrows on paths 6,8 , and 10 in the direction indicated. SES is regarded as causative of Density (path 5) because Density is regarded as being directly affected by housing size, which in turn is partly determined by budgetary constraints reflected in the income component of SES. The direction of the arrow on path 8 is largely determined by theoretical considerations. It may be recalled that the degree of social support was hypothesized to affect 
the development of the type of morbidity, by diminishing density related stress as reflected in lower stress-related morbidity occurrence. Hence the direction of causation must move from Social support to Morbidity Type. SES is seen as a determinant of Social support, based on the idea that Social support may be partly dependent on class-specific value sets which could affect the nature of the interpersonal relationships found in a primary group setting. The concept that Density is a cause of Social Support is based on the idea that beyond some degree of density, Social support as a reducer of stress becomes evident. It may be recalled that this particular hypothesis was not supported by the evidence examined in the preceeding pages. Thus the direction of causation of path 7 is seen as moving from Density to Social Support.

As a final approach to the analysis of these data, Tables XXI, XXII, and XXIII are presented. Table XXI lists the correlation coefficients between the variables, operationalized as outlined in chapter III. Table XXII reoperationalizes the dichotomization of the variables, while Table XXII presents the correlation matrix for these reoperationalized variables. Figure 2 presents the associated path diagram.

It is evident from Table XXI that the primary hypothesis of this thesis, that there exists a direct relationship between the degree of density and the occurrence of stress-related morbidity is not supported. The same conclusion must be drawn for the relationship between age and social support. There is no difference in social support between age categories. Socioeconomic status (SES) also has practically no relationship to the type of morbidity developed. There is a strong 
TABLE XXI

\section{ZERO ORDER CORRELATION COEFFICIENTS BETWEEN \\ DICHOTOMIZED VARIABLES, AS ORIGINALLY \\ OPERATIONALIZED}

\begin{tabular}{|c|c|c|c|c|c|}
\hline & Age & Density & SES & $\begin{array}{l}\text { Social } \\
\text { Support }\end{array}$ & $\begin{array}{l}\text { Morbidity } \\
\text { Type }\end{array}$ \\
\hline Age & - & -0.450 & 0.150 & -0.002 & -0.095 \\
\hline Density & - & - & -0.033 & 0.150 & 0.008 \\
\hline SES & - & - & - & -0.040 & -0.007 \\
\hline $\begin{array}{l}\text { Social } \\
\text { Support }\end{array}$ & - & - & 0 & - & 0.040 \\
\hline
\end{tabular}

relationship, however, between density and age. This is not surprising, given that differences in home density are partly determined by the presence or absence of children, which in turn is partly affected by age or life cycle stage. The economic level achieved by the patient is also related to age. This latter point is borne out by the relationship between age and SES, although the direct relation between SES and density is extremely weak. The strongest single correlation between morbidity type and any other variable is that stemming from age. It can be seen clearly from Table XXI that the effect of density on morbidity type is practically nil. Social support is positively related to density indicating that higher density is associated with higher levels of social support. The relationship between social support and morbidity type is a positive one, although apparently quite weak.

As has been noted in the preceding pages, the directions of change within morbidity types is not consistent. The distortions introduced by this fact led to the selection of representative types 
to re-analyze many of the relationships. Table XXI utilized dichotomized variables which contain much internal variation, making it desirable to reoperationalize some of the variables in the light of what has been found so far, and to apply path analysis techniques. If relationships exist, it may well be that the original operationalization may have produced a masking effect. The reoperationalization of the variables is shown in Table XXII.

TABLE XXII

REOPERATIONALIZATION OF

DICHOTOMIZED VARIABLES

\begin{tabular}{|c|c|}
\hline Variable & Reoperationalization \\
\hline Density & $\begin{array}{l}\text { Low }-0.0 \text { to } 0.50 \text { persons per room } \\
\text { High }-0.51 \text { or more persons per room }\end{array}$ \\
\hline Age & $\begin{array}{l}\text { Younger }-20 \text { to } 34 \text { years of age } \\
\text { Older }-35 \text { or more years of age }\end{array}$ \\
\hline $\begin{array}{l}\text { Social } \\
\text { Support }\end{array}$ & $\begin{array}{l}\text { Low - Index values of } 1 \text { or } 2 \\
\text { High - Index values of } 3 \text { or } 4\end{array}$ \\
\hline $\begin{array}{l}\text { Socioeconomic } \\
\text { Status }\end{array}$ & $\begin{array}{l}\text { Low - Index values of } 1,2,3 \text {, or } 4 \\
\text { High - Index values of } 5,6,7 \text {, or } 8\end{array}$ \\
\hline $\begin{array}{l}\text { Morbidity } \\
\text { Type }\end{array}$ & $\begin{array}{l}\text { Stress-related - Female genitals } \\
\text { Non-Stress Related - Eyes }\end{array}$ \\
\hline
\end{tabular}

The primary alterations which have been made are in the morbidity type and age variables. The prior operationalization combined several morbidity categories into a single type, thus giving rise to the problems previously discussed. The prior operationalization of the age groups had its breaking point at age 45 , the middle of the mature adult category. Social support was previously dichotomized on the basis of marital status, on the theory that being married was equal in 
terms of affective-linked stress reduction to two of the alternative sources of primary group social support. The data presented in Table XXI do not bear out this conceptualization of the relative merits of being married or unmarried. Since this thesis is primarily an inquiry into the nature of the relationships rather than a formal test of hypotheses, it is felt that reoperationalization of this variable is justified, if such reoperationalization can clarify any aspect of the interactions of the variables under consideration. In the new operationalization, the index scores are used without reference to marital status. Table XXIII presents the zero order correlation coefficients derived from the reoperationalized variables.

TABLE XXIII

ZF.RO ORDER CORRELATION COEFFICIENTS BETWEEN

DICHOTOMIZED VARIABLES, AS

REOPERATIONALIZED

\begin{tabular}{|c|c|c|c|c|c|}
\hline & Age & Density & SES & $\begin{array}{l}\text { Social } \\
\text { Support }\end{array}$ & $\begin{array}{l}\text { Ideal } \\
\text { Morbidity } \\
\text { Type* }\end{array}$ \\
\hline Age & - & -0.43 & 0.18 & -0.07 & -0.42 \\
\hline Density & - & - & -0.17 & 0.16 & 0.41 \\
\hline SES & - & - & - & 0.03 & -0.25 \\
\hline $\begin{array}{l}\text { Social } \\
\text { Support }\end{array}$ & - & - & - & - & 0.10 \\
\hline
\end{tabular}

* The sign of the correlation coefficient is determined by the relationship to stress-related morbidity.

It can be seen from Table XXIII that substantial differences emerge through the reoperationalization. This is especially evident in the correlations between density and morbidity type, socioeconomic 
status and morbidity type, and density and socioeconomic status.

Table XXIV sets forth a comparison of the zero order correlation listed in Table XXIII and the regression coefficients calculated from them.

TABLE XXIV

COMPARISON OF ZERO ORDER CORRELATION COEFFICIENTS AND BETA WEIGHTS OF ALL VARIABLES EXAMINED

\begin{tabular}{|c|c|c|c|c|c|c|c|c|c|c|c|}
\hline Relationship & $\begin{array}{l}\text { Zero Orde } \\
\text { Correlati }\end{array}$ & & & & & & & & & \multicolumn{2}{|c|}{$\begin{array}{l}\text { Partial } \\
\text { Regression } \\
\text { Coefficient } \\
\text { (Beta Weight) }\end{array}$} \\
\hline Age to Density & -0.43 & - & . . & • & - & - & - & - & - & - & -0.41 \\
\hline Age to SES & 0.18 & - & . $\cdot$ & - & - & - & - & - & $\cdot$ & - & 0.18 \\
\hline Age to Morb. Type & -0.42 & - & - . & - & - & - & - & - & - & - & 0.29 \\
\hline Age to Soc. Supp. & -0.07 & - & - . & - & - & . & - & $\cdot$ & - & $\cdot$ & 0.0 \\
\hline SES to Density & -0.17 & - & - $\cdot$ & - & - & . & - & • & - & $\cdot$ & -0.11 \\
\hline SES to Soc. Supp. & 0.03 & - & - $\cdot$ & - & - & - & - & $\cdot$ & - & $\cdot$ & 0.0 \\
\hline SES to Morb. Type & -0.25 & - & . . & - & - & - & 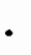 & 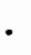 & • & $\bullet$ & -0.20 \\
\hline Dens. to Morb. Type & 0.41 & - & $\cdot \cdot$ & - & - & $\cdot$ & $\cdot$ & ${ }^{\circ}$ & $\cdot$ & ${ }^{\circ}$ & 0.23 \\
\hline Dens. to Soc. Supp. & 0.16 & - & - $\cdot$ & $\cdot$ & - & $\cdot$ & - & • & - & • & 0.16 \\
\hline Soc. Supp. to Morb. & 0.10 & . & - . & • & $\cdot$ & $\bullet$ & & & & & 0.04 \\
\hline
\end{tabular}

Figure 2 presents the path diagram based on information derived from Table XXIV. The standardized regression coefficients presented are partials, with the controls employed being obvious from the diagram. 


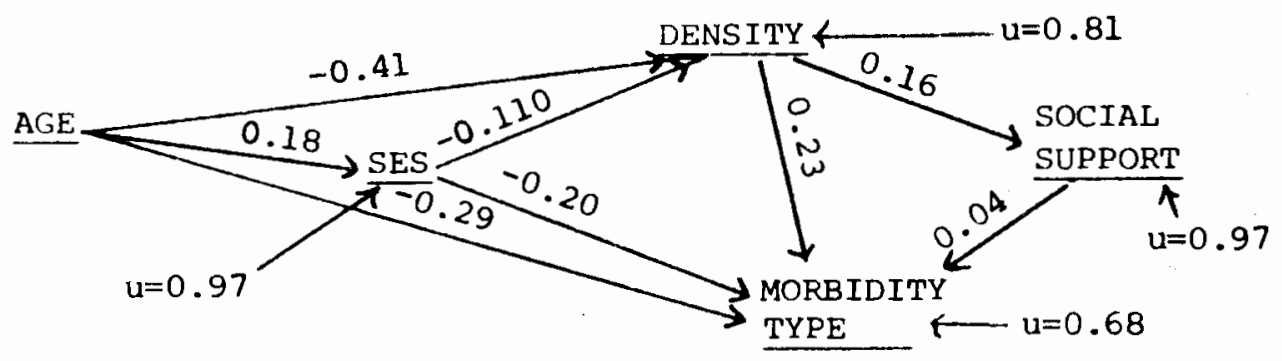

Figure 2. Path diagram for dichotomized variables, as reoperationalized.

It will be noted from Figure 2 that two of the regression coefficients 1 isted in Table XXIV have no counterpart in the beta weights shown on the paths of Figure 2. Both Age to Social Support, controlling for Density, and SES, to Social Support, controlling for Density are very nearly zero, and have thus been excluded as probably spurious. In analyzing Figure 2, it can be seen that density has a considerable impact on morbidity type. This finding is clearly in line with the major hypothesis of this thesis. The sign of the correlations, as found in Table XXIII, as well as their magnitude, also provide information that serves to corroborate the earlier findings from the contingency tables. Age is negatively correlated with density, with a zero order correlation coefficient of -0.43 . This makes sense when we note that higher age is associated with higher socioeconomic status, while socioeconomic status is negatively related to density. It will be recalled that one of the reasons for including socioeconomic status in the model was its anticipated effect on the size of dwelling that could be afforded. This is borne out by the -0.17 correlation coefficient, which indicates that higher socioeconomic status is associated with lower density. Age is also negatively related to density, independent of any effect socioeconomic status may 
have. This relationship of lower age to higher density may be a function of the life stage of the patients. Those in the younger age categories are more likely to have children present in the home, thus increasing the density regardless of the size of the dwelling.

Socioeconomic status is negatively related to the occurrence of the stress-related morbidity. Table $\mathrm{xx}$ indicates that the lower class is overloaded in the regimes of higher density, and thus appears to be more susceptible to density-induced stress. In looking at the partial regression coefficients in Figure 2, it should be noted that the relationship persists. Patients from the lower socioeconomic status group have a higher relative occurrence of stress-related morbidities than do those patients in the upper socioeconomic strata, when age, density, and social support are controlled.

The relationship of density to social support is positive, indicating that higher social support is associated with higher density. This may be accounted for by a factor not measured in this study, but which is implied in both density and social support. It may be recalled that two of the three elements in the social support index are related to the number of people available to assist the patient in his post-discharge recovery. From the positive direction of the coefficient, it is possible that both density and social support are measuring the same element: the number of persons in the patients' households. That this is not entirely the case, however, is indicated by the large difference in the correlations between social support and morbidity type and density and morbidity type. If both variables were measuring exactly the same thing, then the correlations should be nearly identical. The positive sign of the correlation between social 
support and morbidity type does indicate that the hypothesis that stress morbidity occurrence should vary inversely with the degree of social support is clearly not borne out. As previously mentioned in the discussion of the contingency tables, social support does not appear to act as a modifier of density-related stress.

The correlation between density and "ideal" morbidity types gives clear support to the hypothesized relationship between density and stress-related morbiaities. Both the magnitude of the coefficient, as well as its positive sign serve as additional indications that such a relationship does exist at a significant level.

However, it must be clearly borne in mind that this correlation emerged only when two morbidity categories were chosen as being representative of a general type, and that such categories were chosen on the basis of being most representative of the most prevalent deviation ratio pattern found within the morbidity types. This may indicate a lack of generalizability of these findings to the broad range of specific morbidity categories found in either of the two morbidity types. This is indicated by the singular lack of relationship found when all relevant morbidity categories were included in the morbidity types (Table XXI). Nevertheless, a relationship has been found that tends to support the prime hypothesis, even though the relationship is not as all-inclusive as was originally postulated. Table XXIV sets forth the portion of the total variance in the dependent variable (morbidity type) accounted for by the independent variables examined in this thesis. 
TABLE XXV

COEFFICIENTS OF DETERMINATION OF

INDEPENDENT VARIABLES

\begin{tabular}{lcc}
$\begin{array}{l}\text { Independent } \\
\text { Variable }\end{array}$ & $\begin{array}{l}\text { Coefficient of } \\
\text { Determination }\end{array}$ & $\begin{array}{l}\text { Percent of } \\
\text { Explained } \\
\text { Variance }\end{array}$ \\
\hline Age & 0.210 & 668 \\
Socioeconomic status & 0.020 & 6 \\
Density & 0.090 & 28 \\
Social Support & 0.004 & 1 \\
\hline Totals & 0.320 & 1018 .
\end{tabular}

From Table XXV it is evident that Age accounts for more of the variance than any other single independent variable, followed by Density, Socioeconomic Status, and Social Support, in that order. It is also evident that 32 percent of the variance in the dependent variable is accounted for by the four independent variables, leaving 68 percent of the variance in the dependent variable unaccounted for. This should not be surprising, as disease etiology is clearly a combination of many factors. Of perhaps greater interest is the third column of Table XXIV, which indicates the relative explanatory strengths of the independent variables in the model. It will be noted that Density has an explanatory power over four times as great as that of social class. It is also clear that the inexorable process of aging has a far greater effect on morbidity type occurrence than any social or environmental circumstance examined. The low coefficient of determination of Social Support corroborates the earlier findings that 
Social Support has little or no effect on the type of morbidity developed, and thus may be inferred to have insignificant effect on stress reduction. At best, it can only be concluded that the effect of social support on stress reduction cannot be determined through the type of analysis employed in this thesis. 


\section{CHAPTER V}

\section{SUMMARY AND CONCLUSIONS}

Although some conclusions have been put forth in the preceding chapter, it would be advantageous to a more complete understanding of the findings if they were presented in a more compact and systematic foremat. To facilitate this process, the results obtained in Chapter IV are compared with the hypothesized relationships put forth in Chapter II.

Hypothesis 1, Chapter II, states that if other variables are equal, higher levels of density will be associated with a disproportionately high occurrence of stress-related morbidities. It has been found that this relationship holds in only some circumstances, and only for certain morbidity categories. It cannot categorically be asserted that all stress-related morbidities are associated with high degrees of population density. As was indicated in Chapter IV, some stress-related categories are disproportionately represented in regimes of low density. Therefore, the hypothesis cannot be accepted without severe qualifications. In light of the findings of this paper, a modified version of the hypothesis would assert that some stressrelated morbidities are associated with high population density. Taking the stress-related morbidity type as a whole, it was found that more stress-related morbidities were disproportionately represented in regions of high density than were categories within the non-stress related type. Although significant relationships were found, they 
were in general quite weak. It was only when two specific categories were chosen from each morbidity type as representative examples of their respective morbidity type that strong relationships were found. The second hypothesis asserted that higher socioeconomic status should be more closely associated with stress-related morbidities than low socioeconomic status. The data do not support this hypothesis, but rather indicate that low socioeconomic status is associated with disproportionate numbers of stress-related morbidities. The correlative hypothesis, that high degrees of density should be interpreted by higher socioeconomic status patients as more stressful, and that such interpretative mechanisms should find their expression in increased stress-related morbidity occurrence, is likewise not supported. There is some indirect evidence, however, that such differential interpretative schemes are at work, because there are clear differences in the occurrence of stress-related morbidities across social classes. As has been noted, however, the disproportionate occurrence appears in the lower class, not in the upper class as hypothesized.

The third hypothesis stated that age is inversely related to social support. From the data, it would appear that age has little or no relationship to social support. It will be recalled from the discussion in Chapter IV that the Beta weight between Age and Social Support, controlling for Density became zero, and that the zero order correlation was of small magnitude $(-0.07)$.

The final hypothesis put forth the idea that higher levels of social support would be associated with lower occurrence of stress- 
related morbidities. The data clearly do not support this contention. Social support is only marginally related to morbidity type, and the direction of the relationship is in the direction opposite to that postulated in the hypothesis. Social support is directly related to the occurrence of stress-related morbidities. As briefly mentioned in Chapter IV, this may be accounted for by the possibility that both density and social support are measuring some of the same elements. Density is clearly a function of the number of people residing in the patients' homes, and the social support index has as two of its elements the number of persons available to care for patients after discharge from the hospital. It is logical to assume that if more people were residing in the patients' homes, there would be more people to provide care. Thus the social support measure may overlap the density measure. This is partly borne out by the positive correlation coefficient between density and social support.

One of the principal concepts underlying this thesis is that the development of stress-related morbidities is the objective result of patients failing to functionally adapt to environmental stress. A line of reasoning which has not been heretofore mentioned, but which is perhaps as plausible as the foregoing concept, is that the development of such a morbidity itself may be a variety of functional adaptation. The "sick role" removes the patient from the environmental stress through hospitalization, relieves responsibility pressures, and can restructure interpersonal relationships. This particular Iine of reasoning may bear further study.

One area of research into social stress which has received little attention, but which could open doors into fruitful lines of research 
is that dealing with the biological and physiological aspects of social interaction. Although this line of inquiry is not possible using ex-post-facto data, as in this study, and would require an experimental setting, it could prove to be a line of inquiry that would throw increased light on the relationships between environmental circumstance, socio-cultural adaptive mechanisms, and social behavior. If further studies of the same type as this thesis were to be done, alternative approaches might produce more clear cut results. In regard to the operationalization of the dependent variable, that is, Morbidity Type, the findings of this thesis indicate that a more narrow definition of morbidity type produces considerably more significant relationships than when more inclusive categories are used. It might prove worthwhile to examine individual morbidities, such as hypertension, rather than the more inclusive morbidity categories as were used in this study.

Another approach which might be of benefit is to examine the relationship between population density in the home and the occurrence of any type of disease. This would probably involve a random sample of the general population, but might give some indication as to the role played by home population density and general morbidity occurrence. Another aspect ignored in this thesis, but which might have some bearing on moxbidity development is the relationship between internal (home) density and external (area) density and the occurrence of disease in general, or its bearing on differential rates of morbidity type occurrence.

Although the variables examined in this study have some theoretical 
basis for inclusion, it appears that other means of operationalizing them might be an improvement. Social Support is perhaps the best example of this. An accepted measure of group cohesion would probably tap more of the qualities of Social support than the measures employed in this study. Other variables which might have some bearing on morbidity development, such as religosity, as a stress-reduction mechanism, might also be brought into a future study.

The implications of the findings of this study for social policy and urban planning are not overwhelming, but they may be regarded as a minor contribution to a growing body of knowledge in the field of social epidemiology . 


\section{REFERENCES}

Aakster, C.W., "Psychological Stress and Health Disturbances", Social Science and Medicine, Vol. 8, No. 2, Feb. 1974, 77-86.

Allakian, Constance, "Intrusions of Territory and Personal Space: An Exploratory Study of Anxiety Inducing Factors in Hospitalized Patients", International Journal of Psychiatry in Medicine, 1974 (Winter), Vol. 5(1), 27-39.

Altman, Irwin, The Environment and Social Behavior, Brooks/Cole Publishing Co., Montery, Calif. 1975.

American Public Health Association, Committee on Hygiene and Housing "Planning the Home for Occupancy", Public Administration Service Pamphlet, Chicago, I1l., 1950.

Ardrey, R., The Territorial Imperative, Dell Publishing Co., Inc., New York, 1966.

Bajuez, E., "The Pituitary-Adrenocortical System: Its Regulation and Adaptive Functions", in Bajuez, E. (Editor), Physiology and Pathology of Adaptation Mechanisms, Pergamon Press, New York, 1969.

Calhoun, J.B., "Population Density and Social Pathology", Scientific American, 206 (Feb 1962), 139-148.

Carnahan, D., Gave, W., and Galle, O.R., "Urbanization, Population Density, and Overcrowding; Trends in the quality of Life in Urban America", Social Forces, 1974, 53, 1, Sept. , 62-72.

Cassel, J.C., "Social Science Theory as a Source of Hypotheses in Epidemiologic Research", American Journal of Public Health, 54 (1964), 1482-1488.

Christian, J., Flyger, V., and David, D., "Factors in the Mass Mortality of a Herd of Sika Deer Cervus nippon", Chesapeake Science, 1960, 1, 79-95.

Davis, D.E., "Territorial Rank in Starlings", Animal Behavior, 7, $1959,214-221$.

Dodge, David D. and Martin, Walter T., Social Stress and Chronic Illness, University of Notre Dame Press, London, 1970. 
Dodge, David L., "The Location of Diseases on a Stress Continuum: A First Attempt", unpublished article.

Draper, P., "Crowding Among Hunter-Gatherers: The !Kung Bushmen", Science, 82 (Oct. 1973), 301-303.

Edney, Julian J., "Human Territoriality", Psychological Bulletin, 1974, (Dec.), Vol. 81 (12), 959-975.

French, John and Caplan, Robert D., "Psychosocial Factors in Coronary Heart Disease" in Insel, Paul M. and Moos, Rudolf $\mathrm{H}$. (Editors), Health and the Social Environment, D.C. Heath and Company, Lexington, Mass., 1974.

Friedman, Stanford B. and Glasgow, Lowell A., "Psychologic Factors and Resistance to Infectious Disease", in Insel, Paul M. and Moos, Rudolf M. (Editors), Health and the Social Environment, D.C. Heath and Company, Lexington, Mass., 1974.

Galle, O., Gave, W., and McPherson, J.M., "Population Eensity and Pathology; What are its Relations for Man?", Science, April 1972, 23-30.

Gerard, H.B., "Physiological Measurement in Social Psychological Research", in Leiderman, P.H. and Shapiro, D. (Editors), Psychobiological Approaches to Social Behavior, Stanford University Press, Stanford, Calif., 1964.

Gillis, A.R., "Population Density and Social Pathology; the Case of Building Type, Social Allowance, and Juvenile Delinquency", Social Forces, 1974, 53, 2, Dec., 306-314.

Hall, Edward T., The Hidden Dimension, Doubleday and Co., Inc., Garden City, New York, 1966.

Hill, S.R., Goetz, F.C., and Fox, H.M., "Studies on Adrenocortical and Psychological Response to Stress in Man", AMA Archives of Internal Medicine, 97, 1956, 269-298.

Holmes, T.H., and Rahe, R.H., "The Social Readjustment Rating Scale", Journal of Psychosomatic Research, 11: 1967, 206-215.

Hutt, C. and Varzec, M., "Differential Effects of Group Density on Social Behavior", Nature, 209:1966, 137.1-1372.

Jensen, M.M., and Rasmussen, A.F., Jr., "Audiogenic Stress and Susceptibility to Infection" in Welch, B.L. and Welch, A.S. (Editors), Physiological Effects of Noise, Plenum Press, New York, 1970 . 
Kaplan, A.L., "Affective Orientation and Physiological Activity in Small Peer Groups", Psychosomatic Medicine, 25(3), 1963, 245-252.

Kinzel, A.S., "Body Buffer Zone in Violent Prisoners", American Journal of Psychiatry, 127, 1970, 59-64.

Lawrence, John E.S., "Science and Sentiment: Overview of Research on Crowding and Human Behavior", Psychological Bulletin, 1974 (Oct), Vol. 81 (1), 712-720.

Levy, Leo and Herzog, Allen N., "Effects of Population Density and Crowding on Health and Social Adaptation in the Netherlands", Journal of Health and Social Behavior, Vol. 15, Number 3, Sept. 1974, 1201-1232.

Loo, C.M.,"The Effects of Spatial Density on the Social Behavior of Children", Journal of Applied Social Psychology, 2: 1972, 372381 .

, "A Social-Spatial Model of Crowding Stress", in Loo, D.M. (Editor), Crowding and Behavior, MSS Information Corp., New York, N.Y., 1974.

Lyman, Stanford M., and Scott, Marvin B., "Territoriality: A Neglected Sociological Dimension", Social Problems, Vol. 12(12), Fall, 1972 , 101-116.

Mason, J.W., and Brady, J.V., "The Sensitivity of Psychoendocrine Systems to Social and Physical Environment", in Leiderman, P.H. and Shapiro, D. (Editors), Psychobiological Approaches to Social Behavior, Stanford University Press, Stanford, Calif., 1964.

Milgram, Stanley, "The Experience of Living in Cities", Science, Mar. $1970,167,1461-1468$.

Schlachter, S., "The Interaction of Cognative and Physiological Determinants of Emotional States", in Leiderman, P.H. and Shapiro, D. (Editors), Psychobiological Approaches to Social Behavior, Stanford University Press, Stanford, Calif., 1964.

Scotch, N.A., "Sociocultural Factors in the Epidemiology of Zulu Hypertension", American Journal of Public Health, Vol. 53, No. 8, Aug. 1963, 1205-1213.

Shoemaker, H., "Social Hierarchy in Flocks of the Canary", The Auk, $56,19399,381-406$.

Solomon, G.F., and Amkraut, A.R., "Emotions, Stress, and Immunity", in Insel, Paul M. and Moos, Rudolf M. (Editors), Health and the Social Environment, D.C. Heath and Company, Lexington, Mass, 1974. 
Sommer, Robert, "Man's Proximate Environment", Journal of Social Issues, Oct. 1966, Vol. XXII, No. 22, 59-70.

Sommers, Anne R. (Editor), The Kaiser-Permanente Medical Care Program, The Commonwealth Fund, New York, N.Y., 1971.

Stokols, D., "On the Distinction Between Density and Crowding: Some Implications for Further Research", Psychological Review, 79, $1972,275-277$.

Taylor, Leslie R. and Costanzo, Dominic J., "Social Dominance, Adrenal Weight, and the Reticuloendothelial system in Rats", Behavioral Biology, 1975 (Feb.), Vol. 13(2), 167-174.

Tinbergen, N., "Ethology and Stress Diseases", Science, July 1974, Vol. 8, No. 4145, 20-26.

Theorell, T., and Rake, R.H., "Psychosocial Factors and Myocardial Infarction: An Inpatient Study in Sweden", Journal of Psychosomatic Research, 1971, 15, 25-31.

Welch, B.L., and Klopfer, P.H., "Endocrine Variability as a Factor in the Regulation of Population Density", American Naturalist, $95: 1961,256-260$.

Welch, B.L., "Psychophysiological Response to the Mean Level of Environmental Stimulation: A Theory of Environmental Integration", in Walter Reed Army Institute of Research, symposium on Medical Aspects of Stress in the Military Climate, Washington, D.C., April, 1964.

, "Environmental Noise, Adaptation, and Pathological Change", in Welch, B.L. and Welch, A.S. (Editors), Physiological Effects of Noise, Plenum Press, New York, 1970. 


\section{APPENDIX A}

\section{PAIIENT PERSONAL HISTORY QUESTJONMAIRE,}

\section{BESS KAISER HOSPITAL}

TOaAY'S DATE

DLEASE do mOI MARK IN THE SHADED areas

OISREGARD ALL NUMBERS IN PARENTHESES

\begin{tabular}{l|l|l|l|l|l|l|l|l}
\hline 01 & & & & & & \\
\hline$(1-2)$ & $(3-8)$ & $(9)$ & $(10-13)$ & $(14-21)$ & $(22-23)$ & $(24)$ & $(25-30)$ & $(311$ \\
\hline
\end{tabular}

Your cooperation in answering the following questions will aid your physician and wi: 1 privide information to help the Health Plan improve service. Please read the questions carefully $2-4$ i: 11 in the blanks or check the appropriate boxes. Your answers will be strictly confidential. inars you. ADORESS

1. OATE OF BIRTH: (Month, Day \& Year)

$\therefore$ MAT IS YOUR PRESENT MARITAL STATUS: (Please check eppropriate bax)

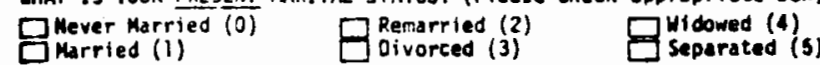

3. WAT SERIOUS ILLNESSES have YOU hADi (Like Pneumonia. Typhoid, etc.)

\begin{tabular}{|c|c|c|}
\hline Orsedse & Oisease \\
\hline
\end{tabular}

4. HOU MANY CHILDREN DO YOU HAVE?

5. HOW MANY PEOPLE LIVE IN YOUR RESIDENCE? (Include yourself)

6. HOU MANY ROOMS ARE IN YOUR RESIDENCE? (Exclude bathroons)

7. D YOU PRESENTLY SMOKE CIGARETTES? $\square$ MO (0) $\square$ YeS (i)

a. IF YOU DON'T SHOKE CIGARETTES NOH, DID YOU EVER REGULARLY SHOKF CIGARETTES? $\square$ No (0) $\square$ Yes (I)

............ IF YES, WHEN DID YOU QUIT SMOKINGT

9. IF YOU SMOKE CIGARETTES MOH, OR IF YOU EVER REGULARLY SMOKED CIGARETTES:

HOU MANY YEARS HAVE YOU SMOKED (OR DID YOU SHOKE)?

HON MANY YEARS HAVE YOU SMOKED (OR DID YOU SHOKE)?
NPPBOXIMATELY HOW HANY CIGARETTES PER DAY DO (DIO) YOU SFOKE?

10. DO YOU REGULARLY SMOKE CIGARS OR A PIPE? $\square$ No (0)

11. DO YOU ORINK ALCOHOLIC BEVERAGES: $\square$ Never (0)

Seldon (1)

$\square$ res (1)

$\square$ Occastonally (2)

$\square$ Dally (4)

12. WHEN YOU DRINK, HOA MANY OF THE FOLLOAING DO YOU USUALLY DRINK OURING A DAY?

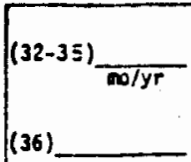

(36)

(2):

(38)

(39)

$(40)+(41)$

(42)

(43)

(44)

$(44)$

(45)

$(46)$

$(4)$

(48)

Drinks

Glasses of wine, and/or

Bottles (glasses) of beer. and/or

of Il quer (49)

13. CORPARE TO LAST YeAR ARE YOU NOW DRINKING: $\square$ More (1) $\square$ Less (2)

$1 \%$ DURING THE LAST YEAR HAVE YOU EVER BEEN WORRIED OR CONCERNED AgOUT YOUR DRINKING? $\square$ HO (0) $\square$ Yes (1)

PLEASE CONPLETE THE QUESTIONS DN THE OTHER SIDE OF THIS FORA

$(50)$

$(51)$

Form 0-1. Revised //75 


\section{APPENDIX A \\ (cont'd)}

15. MON MANY IIMES IN THE PAST THREE YEARS HAVE YOU BEEN HOSPITALIZED? (Exclude this time)

16. BEFORE IHIS ILLNESS WERE YOU: (Check one) ERployed or self moloyed (i) $\square$ Student (4) Dineml oyed (j) If EMPLOYED, WHAT COMPANY DO YOU WORK FOR? YHAT IS IHE SPECIFIC JOB? (if retired, please state fomer occupation)

11. Is rour spouse: (Check one)

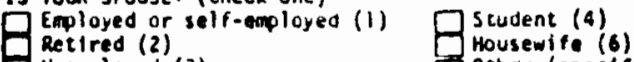
(3) If ENPLYYE, WHAT COMANY? HAT IS THE SPECIFIC JOB?

(1f retired. please state former ocfupdtion)

18. GENERALLY, HOW HOULD YOU COMPARE YOUR HEALTH WITH THAT OF OTHER PEOPLE YOUR AGE BEFORE BEING HOSPITALIZED: $\square$ Excollent (1) $\square$ Fair (3)

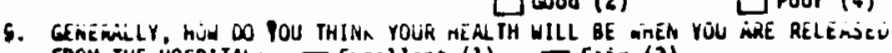
FROH THE HOSPITAL: $\square$ Excellent (1) $\square$ Fair (3)

20. WHEN YOU LEAVL THE MOSPITAL, WILL YOU HAVE SOMEONE 10 HELP YOU: $\square$ Day and Night (1) $\square$ Only for meals and/or occasional chores (4) $\square$ Dight onty (2) $\square$ Port of the day and a night (5)

21. Men yOU leave the hOSPITAL, DO YOU PLAN to GO TO: $\square$ a convalescent or nursing home (1) $\square$ rour own restoence (3) $\square$ a haw of efriend or relative $(2) \square$ other (specify)

22. HAT IS YOUR RELIGIOUS PREFERENCE: $\square$ Protestant (1) $\square$ Jewish (3) ofhek (specify) $\square$ Protestant (1) $\square$ Jewish (3)
offek (specify)
None (0) MAVE YOU GRADUATEO FROM COLLEGE?..... प Yes Ho HOH MaKY TOTAL YEARS OF SCHOOL HAVE YOU COMPLETED? (Count grade school, hlgh school and college)

24. HAS YOUR SPOUSE GRADUATEO FRUY HIGH SCHOOL? ? Yes $\square$ Mo HAS YOUR SPOUSE GRADUATED FROM COLLEGET..... G Yes HOW MAYY TOTAL YEARS OF SCHOOL HAS YOUR SPOUSE COMPLETED? (Count grade school. high school and collegel.

25. WAT IS YOUR TOTA FAMILY INCOME: (Fanlly income is the incone of the head of the fanily plus the income of all relatives in the nousenold.) Under $\$ 2.500$ (01) $\square \$ 10.000-12.499$ (05) $\square \$ 25.000-29.999$ (11) $\square$ Under $\$ 2.500(01) \square \$ 312,500-14.999(06) \square \$ 30.000-34,999(12)$

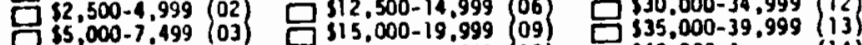
$\square \$, 000-7.499(03) \square(04) \square \$ 20,000-24,999(10) \square \$ \$ 0,000$ iver (14) mis Incone information is used for statistical purposes only.

26. WO COMLLETED THIS QUESTIONNAIRE: $\square$ Patient (1) $\square$ Relative (spectfy) (2) $\square$ Mon-relative (specify)

(5) ) $(54 \cdot 56)$

(FERLEE) 5) $(58-60)$

(61)

(62)

(63) (64) (65) (MLLE) $(66-6))$

(FEMALE) (68-69)

(70) 0 $(71-72)$ (73)

THAMK YOU FOR ANSWERING THESE QUESTIONS. YOUR ANSWERS WILL BE VERY USEFUL TO TOUR PHYSICIAN, THE HOSPITAL NO TO THE HEALTH PLAN. 


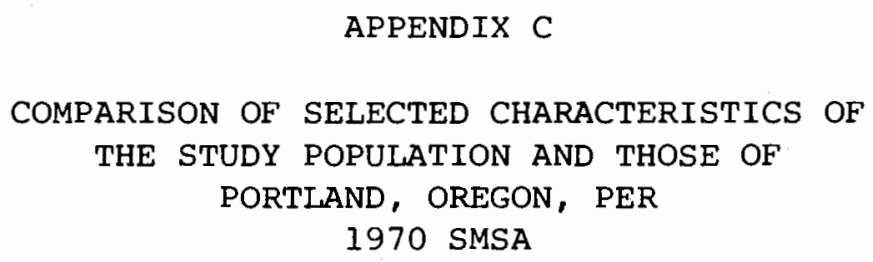

Household Density

Less than 1.01

1.01 to 1.50

1.51 or more

Totals

Total N

$\underline{\text { Age }}$

20 to 34

35 to 59

60 or more

Total

Total $\mathrm{N}$
Portland, Oregon

95.68

3.5

0.9

$100.0 \%$

341,505

Portland, Oregon

32.38

43.8

23.9

100.08

642,741
Study Population

$$
97.9 \%
$$

1.9

0.2

100.08

6327

Study Population

21.28

38.6

40.2

$100.0 \%$

6327 